\title{
Climate change favours connectivity between virus-bearing pest and rice cultivations in sub-Saharan Africa, depressing local economies
}

\author{
Mattia Iannella ${ }^{1}$, Walter De Simone ${ }^{\text {Corresp., } 1}{ }^{1}$, Paola D'Alessandro ${ }^{1}$, Maurizio Biondi ${ }^{1}$ \\ ${ }^{1}$ Department of Life, Health \& Environmental Sciences, University of L'Aquila, L'Aquila, Abruzzo, Italy \\ Corresponding Author: Walter De Simone \\ Email address: walter.desimone@graduate.univaq.it
}

Aims. Rice is a staple food for many countries, being fundamental for a large part of the worlds' population. In sub-Saharan Africa, its importance is currently high and is likely to become even more relevant, considering that the number of people and the per-capita consumption are both predicted to increase. The flea beetles belonging to the Chaetocnema pulla species group (pulla group), a harmful rice pest, are an important vector of the Rice Yellow Mottle Virus, a disease which leads even to $80 \%-100 \%$ yield losses in rice production. We present a continental-scale study aiming at: (1) locating current and future suitable territories for both pulla group and rice; (2) identifying areas where rice cultivations may occur without suffering the presence of pulla group using an Ecological Niche Modelling (ENM) approach; (3) estimating current and future connectivity among pulla group populations and areas predicted to host rice cultivations, based on the most recent land-use estimates for future agricultural trends; (4) proposing a new connectivity index called "Pest Aggression Index" (PAI) to measure the agricultural susceptibility to the potential future invasions of pests and disease; (5) quantifying losses in terms of production when rice cultivations co-occur with the pulla group and identifying the SSA countries which, in the future inferred scenarios, will potentially suffer the greatest losses. Location. Sub-Saharan Africa. Methods. Since the ongoing climate and land-use changes affect species' distributions, we first assess the impact of these changes through a spatially-jackknifed Maxent-based Ecological Niche Modelling in GIS environment, for both the pulla group and rice, in two climatic/socioeconomic future scenarios (SSP_2.45 and 3.70). We then assess the connectivity potential of the pulla group populations towards rice cultivations, for both current and future predictions, through a circuit theorybased approach (Circuitscape implemented in Julia language). We finally measure the rice production and GPD loss per country through the spatial index named "Pest Aggression Index", based on the inferred connectivity magnitude. Results. The most considerable losses in rice production are observed for Liberia, Sierra Leone and Madagascar in all Peer reviewing PDF | (2021:07:63869:1:0:NEW 14 Sep 2021) 
future scenarios $(2030,2050,2070)$. The future economic cost, calculated as USD lost from rice losses/country's GDP results are high for Central African Republic (-0.6\% in SSP_2.45 and $-3.0 \%$ in SSP_3.70) and Guinea-Bissau (-0.4\% in SSP_2.45 and $-0.68 \%$ in SSP_3.70), with relevant losses also obtained for other countries. Main conclusions. Since our results are spatially explicit and focused on each country, we encourage careful land-use planning. Our findings could support best practices to avoid the future settlement of new cultivations in territories where rice would be attacked by pulla group and the virus, bringing economic and biodiversity losses. 
1 Climate change favours connectivity between virus-bearing pest and

2 rice cultivations in sub-Saharan Africa, depressing local economies.

4 Mattia Iannella $^{1}$, Walter De Simone ${ }^{{ }^{*}}$, Paola D'Alessandro ${ }^{1}$ and Maurizio Biondi ${ }^{1}$

$6 \quad{ }^{1}$ Department of Life, Health \& Environmental Sciences, University of L’Aquila, Via Vetoio -

7 Coppito, 67100 L’Aquila, Italy

8

9 Email addresses: mattia.iannella@univaq.it (M.I.); walter.desimone@graduate.univaq.it

10 (W.D.S.); paola.dalessandro@univaq.it (P.D.); maurizio.biondi@univaq.it (M.B.).

12 Corresponding author:

13 Walter De Simone ${ }^{1^{*}}$

14 Via Vetoio - Coppito, L’Aquila, 67100, Italy

15 E-mail address: walter.desimone@graduate.univaq.it (W. De Simone)

16 ORCID iD: 0000-0003-0323-0920

17 


\section{Abstract}

27 Aims. Rice is a staple food for many countries, being fundamental for a large part of the worlds' population. In sub-Saharan Africa, its importance is currently high and is likely to become even more relevant, considering that the number of people and the per-capita consumption are both predicted to increase. The flea beetles belonging to the Chaetocnema pulla species group (pulla group), a harmful rice pest, are an important vector of the Rice Yellow Mottle Virus, a disease which leads even to $80 \%-100 \%$ yield losses in rice production. We present a continental-scale study aiming at: (1) locating current and future suitable territories for both pulla group and rice;

(2) identifying areas where rice cultivations may occur without suffering the presence of pulla group using an Ecological Niche Modelling (ENM) approach; (3) estimating current and future connectivity among pulla group populations and areas predicted to host rice cultivations, based on the most recent land-use estimates for future agricultural trends; (4) proposing a new connectivity index called "Pest Aggression Index" (PAI) to measure the agricultural susceptibility to the potential future invasions of pests and disease; (5) quantifying losses in terms of production when rice cultivations co occur with the pulla group and identifying the SSA countries which, in the future inferred scenarios, will potentially suffer the greatest losses.

Location. Sub-Saharan Africa.

Methods. Since the ongoing climate and land-use changes affect species' distributions, we first assess the impact of these changes through a spatially-jackknifed Maxent-based Ecological Niche Modelling in GIS environment, for both the pulla group and rice, in two climatic/socioeconomic

46 future scenarios (SSP_2.45 and 3.70). We then assess the connectivity potential of the pulla

47 group populations towards rice cultivations, for both current and future predictions, through a 48 circuit theory-based approach (Circuitscape implemented in Julia language). We finally measure 
49 the rice production and GPD loss per country through the spatial index named "Pest Aggression

50 Index”, based on the inferred connectivity magnitude.

51 Results. The most considerable losses in rice production are observed for Liberia, Sierra Leone

52 and Madagascar in all future scenarios (2030, 2050, 2070). The future economic cost, calculated

53 as USD lost from rice losses/country’s GDP results are high for Central African Republic (-0.6\%

54 in SSP_2.45 and -3.0\% in SSP_3.70) and Guinea-Bissau (-0.4\% in SSP_2.45 and $-0.68 \%$ in

55 SSP_3.70), with relevant losses also obtained for other countries.

56 Main conclusions. Since our results are spatially explicit and focused on each country, we

57 encourage careful land-use planning. Our findings could support best practices to avoid the future

58 settlement of new cultivations in territories where rice would be attacked by pulla group and the

59 virus, bringing economic and biodiversity losses.

60

61 Keywords: Rice Yellow Mottle Virus, Chaetocnema pulla species group, rice production,

62 Shared Socioeconomic Pathway, climate change, ecological niche modelling, GIS analysis, sub-

63 Saharan Africa

Introduction

67 Rice is one of the most cultivated crops globally, representing a fundamental source of livelihood 68 for a large part of the world's population (Chauhan, Jabran \& Mahajan, 2017). Its cultivation is

69 very different in both techniques and environments, ranging from single-crop systems (temperate

70 and tropical regions, in rainfed and irrigated conditions) to intensive monoculture (irrigated areas,

71 in the tropics) (Chauhan, Jabran \& Mahajan, 2017).

72 The African continent is very far from food self-sufficiency, a condition predicted to worsen in

73 the next future, considering the current sociodemographic pressure (Mbow et al., 2019). As rice 
74 is today considered a staple food for many African countries, considering both population growth

75 and per-capita consumption, rice crops are predicted to expand (Mbow et al., 2019).

76 Sub-Saharan Africa (SSA) comprises some of the poorest regions in the world; policy makers,

77 donors and other partners have implemented several food strategies over the years in this area,

78 including strengthening the rice sector, which has been identified as a vital component of food

79 security and poverty reduction (Jayne \& Rashid, 2013; deGraft Johnson et al., 2014). Rice is

80 rapidly gaining importance as a staple food and is now one of the major sources of food energy in

81 SSA, being used by over 750 million people in this region (FAO, 2017).

82 The coupled effect of climate change and land-use alterations (e.g. urban settlements, logging

83 forests) is leading to biodiversity loss on both global and local scales (Iannella, Liberatore \&

84 Biondi, 2016; Griscom et al., 2018). These biodiversity variations exert pressure on agro-

85 ecosystems, altering their functionality with consequent loss of ecosystem services, which are a

86 part of the conditions and processes by which ecosystems (both natural and semi-natural) support

87 and provide services to humankind. They can be divided into several categories: regulating,

88 cultural, support, and provisioning services (e.g. food, fiber, and biofuels) (Carpenter et al.,

89 2006).

90 Agricultural production (rice, in this case) is the most clearly observable supply service, based on

91 crop yield. Thus, the potential of rice supply as an ecosystem service can be defined as the

92 maximum (hypothetical, considering the environmental constraints) yield of rice (Burkhard et al.,

93 2014).

94 Rice production and the provision of related ecosystem services are highly dependent on

95 environmental and socio-economic factors; still, some knowledge gaps occur among decision-

96 makers for developing sustainable agriculture strategies and improving food security (FAO,

97 2017). These led to increased environmental risks (e.g. drought, erosion, pollution, and pests), as

98 well as threats of famine in developing countries (Mbow et al., 2019). Moreover, current climate 
99 change is affecting (and is predicted to affect) the frequency of precipitation, the UV-B radiation

100 and intensity of droughts, directly influencing the relationships between rice and its pests and

101 diseases (Haq et al., 2010). Among these last, the Rice Yellow Mottle Virus (RYMV) is the

102 leading viral rice disease and the primary viral constraint to rice production in Africa

103 (Koudamiloro et al., 2015), and different approaches were used to infer its potential spread

104 (Trovão et al., 2015; Dellicour et al., 2018). Research has shown that, among RYMV vectors

105 (Traore et al., 2009), leaf-feeders insects found in rice paddies are the main source of virus

106 transmission (Heinrichs, 2004; Koudamiloro et al., 2015), with many studies reporting their

107 involvement in the spread of this disease also on a landscape scale (Heinrichs, 2004;

108 Rakotomalala et al., 2019).

109 Among pests, Chaetocnema pulla species group sensu Biondi and D’Alessandro (2008)

110 (hereafter, pulla group), flea beetles (Chrysomelidae, Galerucinae, Alticini) occurring in most of

111 the Afrotropical region including Madagascar, and in the Arabian Peninsula (Saudi Arabia and

112 Yemen), are a particularly harmful pest of rice (Oryza sativa) (Biondi, 2001). Also, they

113 represent an important vector of the RYMV in SSA (Bakker, 1971; Koudamiloro et al., 2015);

114 moreover, Banwo et al. (2001) report that if specimens of pulla group abundantly occur when an

115 RYMV source is present, a vast spread of the virus is expected. Rice yellow mottle virus and can

116 cause up to 80\% - 100\% yield loss in some rice-cropping systems (Wopereis et al., 2013; Asante

117 et al., 2020), with a decrease in the number of spikelets, the partial or total sterility of the rice

118 panicles, and the death of the infected plant (Kouassi et al., 2005).

119 Despite the high economic importance of rice crops and its food security implication, no large-

120 scale studies has been done to date; indeed, some local-scale research about the co-occurrence of

121 RYMV and insects in the context of rice production was published (Kouassi et al., 2005;

122 Balasubramanian et al., 2007; Hubert, Lyimo \& Luzi-Kihupi, 2017). Moreover, there are no 
123 predictions of future distribution trends for pests, disease, and available rice areas, especially

124 under climate and land-use change scenarios.

125 Considering these gaps in knowledge, we present a continental-scale study aiming at: (1) locating

126 current and future suitable territories for both pulla group and rice; (2) identifying areas where

127 rice cultivations may occur without suffering the presence of pulla group using an Ecological

128 Niche Modelling (ENM) approach; (3) estimating current, and future connectivity among pulla

129 group populations and areas predicted to host rice cultivations, based on the most recent land-use

130 estimates for future agricultural trends; (4) proposing a new connectivity index called "Pest

131 Aggression Index” (PAI) that measuring the agricultural susceptibility to the potential future

132 invasions of pests and disease; (5) quantifying losses in terms of production when rice

133 cultivations co occur with the pulla group, and identify the SSA countries which, in the future

134 inferred scenarios, will potentially suffer the greatest losses.

136 Materials \& Methods

137 Target species and study area

138 Chaetocnema Stephens, 1831 is a flea beetle genus widespread in all zoogeographical regions. It

139 consists of over 300 described species. About the Afrotropical region, Chaetocnema genus

140 includes over 100 known species (Biondi, 2002; Biondi \& D’Alessandro, 2006a,b, 2018). The

141 species of this genus are often associated with moist environments and plants in many botanical

142 families, particularly the Chenopodiaceae, Polygonaceae, Cyperaceae, Gramineae (Biondi,

143 Urbani \& D’Alessandro, 2015). A small group of very similar species (Biondi \& D’Alessandro,

144 2008), including Chaetocnema pulla Chapuis, 1879, C. nkolentangana Bechyné, 1955, C.

145 subquadrata Jacoby, 1897, and C. vanschuybroecki Biondi \& D’Alessandro, 2008, widespread in

146 the Afrotropical region, are here considered. The occurrence localities of pulla group were 
147 mainly obtained from Biondi \& D’Alessandro (2008) and integrated with new data (M. Biondi,

148 personal data), obtaining the most complete dataset for this taxon to date.

149 About the target plant species, two main species of rice are cultivated in Africa. The first is

150 Oryza sativa L., native to Asia and was introduced in Africa about 450 years ago. Another lesser-

151 known species, O. glaberrima Steud, is native to Africa and was domesticated in the Niger River

152 Delta (in northern Mali) over 3000 years ago. As a result of their evolution and domestication,

153 both species have distinct and complementary advantages and disadvantages for African farming

154 systems. Asian rice (O. sativa) is characterized by good yields, no entrapment and crushing of

155 grain, and high fertilizer yields, unlike its African counterpart (O. glaberrima). However, unlike

156 Asian rice types, native varieties of O. glaberrima often have good competitiveness and weed

157 resilience against major African biotic and abiotic stresses (Koffi, 1980; Jones, Mande \& Aluko,

158 1997). The study area is sub Saharan Africa, where the two target taxa both occur.

160 Ecological Niche Modelling

161 To estimate the current and future climatic suitable area of both pulla group and rice, Ecological

162 Niche Models were built; these have recently gained popularity among many fields of natural

163 sciences, as they permit to better address conservation policies (Iannella et al., 2018; Brunetti et

164 al., 2019), understand biogeographic patterns (Iannella, Cerasoli \& Biondi, 2017; Console et al.,

165 2020) and predict possible distribution of invasive species and pests (Fick \& Hijmans, 2017).

166 For this aim, nineteen bioclimatic variables for current climatic conditions were downloaded

167 from the Worldclim.org repository, ver 2.1 (Fick \& Hijmans, 2017), at 2.5 arc-minutes

168 resolution. To avoid possible correlation among predictors, which may lower model's

169 performance, both Variance Inflation Factor (VIF, threshold set $=10$ following Guisan et al.

170 (2017)) and Pearson’s r $(|r|<0.85$, following Dormann (2007); Elith et al. (2006)) were assessed 
171 through the 'vifstep' and 'vifcor' functions of the 'usdm' R package (Naimi, 2015), and a subset

172 of predictors was then used for models’ calibration.

173 Ecological Niche Models were built through the Maxent (Phillips, Anderson \& Schapire, 2006)

174 implementation in "SDMtoolbox” 2.4 version (Brown, Bennett \& French, 2017), in ArcMap 10.0

175 (ESRI, 2010). This software permits to take advantage of the powerful machine-learning

176 algorithm of Maxent and to integrate into the modelling process some details (not available on

177 the "standard” version of Maxent), which increase models' discrimination power by lowering

178 spatial biases. In particular, the 'Spatial jackknifing' procedure implemented in this software

179 permits to reduce spatial autocorrelation among data by splitting the study area (and the

180 corresponding presence occurrences and background points) into training and test datasets,

181 iteratively (Brown, Bennett \& French, 2017). For the present study, 5 spatial jackknife groups

182 were set; moreover, considering the great extent of the study area, a bias mask to account for and

183 correct the latitudinal bias was generated through the 'Bias File for Coordinate Data (BFCD) in

184 MaxEnt' algorithm (Brown, Bennett \& French, 2017) and applied to the modelling process.

185 Before being used as input data for the models, both pulla group and rice occurrence data were

186 processed through the 'Spatially Rarefy Occurence Data for SDMs' algorithm (resolution = 10

$187 \mathrm{~km}$ ) so as to make comparable the resolution of occurrences with one of the predictors (Sillero \&

188 Barbosa, 2020). To obtain reliable estimates, 10 replicates for each model parameter class were

189 calculated, and a Regularization Multiplier = 5 was set, for a total of 250 single models for each

190 species. Also, spatially segregated groups were chosen, as this option permits the models'

191 training and evaluation in potentially non-analogous environments (Brown, Bennett \& French, 192 2017).

193 Models trained on current climate were projected to future conditions using three different

194 general circulation models (GCMs) to reduce uncertainties due to their differences (Stralberg et

195 al., 2015). For this aim, 2030, 2050 and 2070 GCM projections of BCC-CSM2-MR (Wu et al., 
196 2019), the IPSL-CM6A-LR (Boucher et al., 2020) and the MIROC6 (Tatebe et al., 2019) were

197 chosen, for two Shared Socioeconomic Pathways (SSP), the SSP245 and the SSP370. These were

198 chosen based on their link between the possible future trends of land-use (see below) and two

199 Representative Concentration Pathways (RCPs) scenarios, with a more optimistic (RCP 4.5) and

200 a "middle of the road" one (RCP 7.0). Moreover, the Multivariate Environmental Surface

201 Similarity (MESS, following Elith and Leathwick (2009)), which measures the projected models’

202 degree of extrapolation (i.e. the divergence of environmental predictors used for models

203 calibration with respect to the ones used for models projections), was taken into account. This

204 information was incorporated into the MEDI, an index used to proportionally weigh future

205 models' projections based on their degree of extrapolation measured through the MESS (Iannella,

206 Cerasoli \& Biondi, 2017). Models’ discrimination power was assessed by both the Area Under

207 the Curve of the Receiver Characteristic Operator obtained from the Maxent output (Phillips,

208 Anderson \& Schapire, 2006) and the continuous Boyce index (ranging from $-1=$ counter

209 prediction to $+1=$ optimal prediction), which is the best choice for evaluating presence-only

210 ENMs (Boyce et al., 2002; Hirzel et al., 2006). This was calculated through the 'ecospat.boyce'

211 function of the 'ecospat’ package (Di Cola et al., 2017) in R environment (R Core Team, 2016).

212

213 Land-Use simulations and GIS analyses

214 The ENMs obtained were further analysed in a GIS environment to refine the predictions in more

215 realistic distribution scenarios of both target taxa (Iannella et al., 2019). All analyses of this

216 section were performed in QGIS 3.10.11 (QGIS Development Team, 2021).

217 We performed future land-use-land-cover (LULC) simulations in sub-Saharan Africa using the

218 InVEST suite, a geospatial modelling framework tool that evaluates the impact of land-use

219 change on ES (Sharp et al., 2018; De Simone et al., 2020). 
220 Furthermore, we evaluated rice production under the influence of pulla group in different future

221 scenarios (SSP2 and SSP3 narratives) within a time range of 40 years (2030 - 2050 - 2070).

222 The basic LULC we have chosen for all the analyses performed is the Global Land Cover 2010

223 (used as a current scenario), distributed by the Copernicus Climate Change Service (C3S), which

224 classifies the earth's surface into 22 classes with a spatial resolution of $0.002778^{\circ}(\sim 300 \mathrm{~m})$.

225 In addition to the map described above, to identify the rice crops more precisely, we used the

226 SPAM (Spatial Production Allocation Model) map 2010 (Yu et al., 2020), isolating the "rice"

227 class from other crops. Using GIS techniques, it was fused with C3S's "rainfed/irrigated

228 cropland" class to create an additional land-use category (called Rice) representing potential rice

229 crops of the current situation.

230 To obtain simulations of future LULC maps, the 'Scenario Generator proximity-based' (SGpb) of

231 the InVest suite (Sharp et al., 2018) was used. This tool allows to create simulations of possible

232 alternative futures using the data provided by the user.

233 Following the creation of the new Rice class, we translated management policies into spatial data

234 using "guidelines" ("storylines"). To this end, the SSP was used. In particular, the SSP database

235 (SSPdb) of Riahi et al. (2017) was used, which quantifies the mitigation policies. This database

236 was created to model and compare possible future trajectories of different LULC and climatic

237 scenarios (deriving from RCP + SSP) and quantify such changes.

238 Future LULC scenarios have been built to strengthen the link between the SSP narratives and the 239 new RCP scenarios, to have more precise information about future projections.

240 The socio-economic scenarios chosen were SSP2 4.5 and SSP3 7.0, and the new Rice class

241 previously created was selected for the future simulations. Given the unavailability of the SSP3

2427.0 scenario in SSPdb, we used the baseline SSP3 data because Fujimori et al. (2017) indicated

243 that the case with a forcing level of $7.0 \mathrm{~W} / \mathrm{m}^{2}$ roughly corresponds to the SSP3 baseline cases. 
244 To extract the real values of the rice crops area for our study region, we used the FAOSTAT 245 database (FAO, 2016). To obtain the future growth rate of rice crops area, we performed a linear 246 regression analysis on the data obtained by FAOSTAT $(1973 \div 2010)$. We then performed a ratio

247 between the cultivated areas of the SSPdb and those of the current LULC to obtain the data for 248 future simulations of the land-use scenarios.

249 We considered the Croplands variation in millions of hectares for two SSP narratives: SSP2 and 250 SSP3. In SSP2 (midway), land-use change is incompletely regulated, i.e., tropical deforestation 251 continues, albeit with slow decline rates; crop yield rates slowly increase over time (Fricko et al., 252 2017).

253 The second SSP narrative considered, SSP3 (regional rivalry), shows a resurgent nationalism, 254 concerns about competitiveness and security, and pushes countries to focus more and more on 255 national or regional issues. Land-use change is hardly regulated and crop yield rates decline 256 sharply over time, mainly due to the minimal transfer of new agricultural technologies to 257 developing countries (Fujimori et al., 2017).

258 The values for the correct setting of the SGpb tool were obtained by calculating the variation 259 (2010 $\div 2030 ; 2030 \div 2050 ; 2050 \div 2070)$ between the present and future rice areas.

260 To simulate the future LULC, we applied the two SSP projections to cultivated land in the LULC 261 classes that are most likely to be modified (see below) closer to existing cultivated land. Three 262 types of land cover were chosen: (a) "Focal ground cover" (SGpb tool converts classes from the 263 edge of focal land cover zones) was chosen based on the most likely categories to increase 264 agricultural areas. It is more likely to extend agriculture from existing crops than to create new 265 ones. (b) "Convertible land cover" represents the types of land cover that can be converted, 266 chosen based on the classes that have changed the most in the last 20 years, and obtained from 267 the analysis of these LULC variations (ESA, 2017). (c) "Replacement land cover" was chosen 
268 because the agricultural land cover class was the most frequently converted compared to the other

269 LULC categories (De Simone et al., 2020).

270 To identify the areas of co-occurrence for the correct MEDI models (pulla group and rice), we

271 polygonized and intersected them with the simulations of future scenarios

272 (LULC_2030_SSP2_4.5, LULC_2050_SSP2_4.5, $\quad$ LULC_2070_SSP2_4.5,

273 LULC_2030_SSP3_7.0, LULC_2050_SSP3_7.0 and LULC_2070_SSP3_7.0).

274 From the spatial data obtained, we calculated the resulting rice crops area values to estimate the

275 surface area most affected by the pest and to evaluate the co-occurrence between the two taxa

276 within each sub-Saharan African country.

278 Landscape connectivity

279 To assess the potentiality of the study area in allowing the current and future colonization of rice

280 cultivations from where pulla group currently occurs (i.e. measuring landscape connectivity for

281 pest invasion), Circuitscape v.5 (Anantharaman et al., 2020) in Julia 1.5.3 programming language

282 (Bezanson et al., 2017) was used.

283 Circuitscape applies both random walks and circuit theory to model the ecological connectivity in

284 a target area (McRae et al., 2008; McRae, Shah \& Edelman, 2016) and is particularly useful and

285 robust, with respect to other connectivity software, for applications in which the species has no

286 previous knowledge of the route to use for the colonization (McClure, Hansen \& Inman, 2016),

287 as in this case.

288 For this aim, the ENMs outputs were converted into friction maps (the inverse of suitability

289 maps) through the 'Raster calculator' tool in ArcMap 10.0 and used as resistance layers (i.e., the

290 resistance which a landscape has to the movement of target individuals/taxa). The 'Advanced'

291 mode was used to enable the activation of independent sources (pulla group occurrence localities)

292 and grounds (the destination patches, in our case, the current and future predicted rice 
293 cultivations in raster format). Considering the great geographic extent of the study area, the

294 'solver = cholmod' (a solver method applying a Cholesky decomposition) was used (Bezanson et

295 al., 2017). The outputs obtained are raster maps depicting a current value, which were

296 subsequently managed in ArcMap 10.0.

297 Pest aggression index (PAI) and provisioning ecosystem services

298 To go further into the understanding of the consequences of the connectivity which the landscape

299 offers to the invasion of pulla group to rice cultivations, we developed an appropriate index,

300 which we call "Pest Aggression Index" (PAI), calculated through the corridor edge (CE) and

301 Mean Corridor Magnitude (MCM, whose rationale is reported in Fig. 1), the parameters of which

302 are introduced and detailed below.

303 When referred to target countries $\left(\mathrm{PAI}_{\text {Country}}\right)$, to obtain a single value for a target area (in our

304 case, a country, even though the PAI can be applied to any territory), we first process the

305 connectivity maps inferred in the previous steps. Considering that these are continuous rasters

306 spanning the whole study area (Fig. 1A), we remove zero values to isolate each corridor from

307 another (Fig. 1B). Then we calculate the mean cell raster value in R (R Core Team, 2016),

308 obtaining a single number that represents the magnitude of an ideal vector which symbolizes the

309 corridor, a value we name Mean Corridor Magnitude (MCM) (Fig. 1C). The MCM is then used

310 to set the threshold of the continuous corridor rasters. Concurrently, we consider the length (in

$311 \mathrm{~km}$ ) of the corridor edge (CE), which is in contact with the destination rice patch, representing

312 the "frontline” which the pests will first find, moving through the landscape corridor (Fig. 1C).

313 To standardize the results and compare the PAI for each country, we refer to the multiplication of

314 these first two terms to the total rice cultivation (RP) and agricultural area (AR) of the target

315 country through the formula: 


$$
\mathrm{PAI}_{\text {Country }}=\frac{\sum_{i=1}^{n} C E_{i} * M C M_{i}}{\text { Total RP } P_{\text {Country }} * \text { Total } A R_{\text {Country }}}
$$

317 The PAI $_{\text {Country }}$ is divided by the maximum value of each year_SSP scenario and further

318 normalized by subtracting the obtained value from 1 . Then, the value obtained is multiplied by

319 the rice production of each country, obtaining a "weighted" one, which mirrors the potentiality

320 that the pulla group populations have to reach and affect cultivations.

321 This index ranges from zero (no landscape connectivity among the pest's populations and target

322 cultivations) to 1 (the highest PAI, the highest expected losses to cultivations in each country).

323 Considering the data achieved from the previous analyses, we calculated the future potential rice

324 production (FPRP) in the different scenarios (SSP2 4.5 2030-2050-2070 and SSP3 7.0 2030-

325 2050-2070) for each sub-Saharan country. We calculated the FPRP by multiplying the areas of

326 the rice patches (in co-occurrence with the pulla group) with the average rice yield (ton/ha). As

327 previously done to obtain the growth rate of rice crops area, to calculate the rice yield's future

328 growth rate, we performed a linear regression analysis on the data obtained by FAOSTAT (1973 $329 \div 2010)$

330 To obtain the final values of loss in rice production (provisioning ecosystem service), we 331 calculated for each country the difference between the total FPRP (without pulla) and the FPRP 332 values obtained under the influence of pulla. Furthermore, to standardize these values, we 333 multiplied the final value by the PAI values (by country and LULC scenario). We have 334 condensed the loss in rice production (\%) obtained by the countries in a heatmap (Fig. 5A, B) 335 achieved through the Seaborn library in the Python environment (Waskom, 2021).

336 To achieve a more accurate view of the economic losses by country, we also calculated the ratio 337 between the economic loss and the gross domestic product (GDP) for each nation (Fig. 5A, B). 338 We used the obtained economic loss data and the projected GDP values to the future taken from 
339 the SSPdb, Faostat and WFP VAM (“WFP VAM,” 2017) database. A selection of countries was

340 made both for the results obtained and for the availability of the various data sources (rice price,

341 GDP).

342

343 Results

\section{Models calibration and evaluation}

345 After the variables' selection process, 9 bioclimatic variables were selected for the models'

346 calibration, namely BIO1 (mean annual temperature), BIO2 (mean diurnal range), BIO3

347 (isothermality), BIO8 (mean temperature of wettest quarter), BIO13 (precipitation of the wettest

348 month), BIO14 (precipitation of driest month), BIO15 (precipitation seasonality), BIO18

349 (precipitation of warmest quarter) and BIO19 (precipitation of coldest quarter). The models built

350 on this set of variables resulted in high discrimination power, with an AUC $=0.817$ for Oryza

351 and AUC $=0.807$ for pulla group (Fig. S1A) and the Continuous Boyce Index obtained for

352 Oryza $=0.983$ and for pulla group $=0.957$ (Fig. S1B). Moreover, low spatial standard deviation

353 resulted for both the models calibrated on the current climatic conditions (Fig. S1C, D).

355 Current distribution and future co-occurrences

356 The occurrence localities of pulla group are clustered in specific areas, mainly Central-Eastern

357 and Western Africa, as well as Madagascar, while rice is widely cultivated (obtained from

358 Gbif.Org, 2020; accessed on November 18, 2020), even in territories where pulla group does not 359 occur (Fig. 2).

360 These distributions are partially mirrored in the areas obtained through the ENMs. The 361 combinations of the low, medium, and high suitability classes report broad areas in which

362 cultivations in both Western and some territories of Eastern Africa may not currently suffer the 363 presence of pulla group (Fig. 3). 
364 The general trend of vast areas hosting the conditions mentioned above disappears in future

365 projections (Fig. 4A-F). Instead, an increase in the Mid-Mid, Mid-High and High-Mid suitability

366 classes (intended as pulla-rice) is observed. For instance, the SSP_2.45 shows a +68\% of the

367 Mid-High class in the 2030 scenario (Fig. 4A), with some peaks observed in the 2070 SSP_3.70,

368 where the Mid-Mid class reaches an increase of $+84 \%$ (Fig. 4F).

369

370 Connectivity of pests to rice cultivations and provisioning ecosystem services

371 The landscape connectivity inferred from future scenarios show corridors allowing pulla group to

372 reach rice cultivations in specific African territories, such as Nigeria, Cameroon, Sudan, South

373 Sudan, Democratic Republic of Congo, Zimbabwe, Republic of South Africa, and Madagascar

374 (Fig. A.2).

375 The Pest Aggression Index (PAI) values ranged from 0 to 0.992; these values were used to obtain

376 the rice production loss (in percent) for each SSA country, as summarized in the heatmaps

377 reported in Fig. 5A, B. Different results are observed according to the SSP scenario (2.45 and

378 3.70). The production loss for the SSP 2.45 and SSP 3.70 narratives (Fig. 5A, B) shows that the

379 countries that will suffer the largest production losses ( $>-90 \%)$ in all the scenarios analyzed

380 (2030, 2050, 2070) are Liberia and Sierra Leone. In the SSP 2.45 scenario, other countries such

381 as Madagascar, Guinea, Côte d'Ivoire, Ghana and Guinea-Bissau (only in 2070) show losses

382 between 65 to $83 \%$. In the SSP 3.70 scenario (Fig. 5B), the same countries recorded a similar loss

383 of rice production to the SSP 2.45 scenario, with the addition of the Central African Republic,

384 Togo and Guinea-Bissau. Some countries, such as the Democratic Republic of Congo and

385 Cameroon, show average loss values (46-54\%) only in the SSP 3.70_2070 scenario.

386 Concerning the ratio between production loss and GDP (Fig. 5A, B; stacked-bars), the condition

387 is still different, as emerging from the heatmap. In the SSP 2.45 narrative (Fig. 5A), the countries

388 showing the most considerable losses ( -0.95\%) are the Central African Republic, Guinea- 
389 Bissau, Liberia, Madagascar, Gabon, the Democratic Republic of Congo and Mozambique

390 (respectively, in descending order). In the SSP 3.70 scenarios (Fig. 5B), harsh economic losses

391 are predicted to reach a net value of $-4.8 \%$, with the Central African Republic (highest absolute

392 values), Guinea-Bissau, the Democratic Republic of the Congo, Chad, Liberia, Mozambique,

393 Madagascar and Gabon being the more affected by the loss. The Central African Republic is the 394 only country showing a notable increase in 2070 (+ 0.82\%) (Fig. 5B).

\section{Discussion}

397 Our results show a diversified, complex geographic asset of rice’s suitable territories with respect

398 to the ones of the pulla group, its virus-bearing pest. Rice is cultivated in different environments,

399 from hot and humid alluvial plains to high mountain ranges (up to about $2700 \mathrm{~m}$ ), from the 400 equator to high latitudes (about 53 degrees), in four different farming systems (rain-fed lowland, 401 lowland, irrigated, upland rice and mangrove-rice fields) (Oteng, Sant’Anna \& Van Tran, 1999). 402 In SSA, about $40 \%$ of rice cultivations occur in the uplands (contributing 19\% to total rice 403 production, thus attaining the lowest potential yields), 37\% in the rainfed lowlands (contributing $40448 \%$ to total rice production) and 14\% in the irrigated territories (contributing 33\% to total rice 405 production); the remaining 9\% is managed through the mangrove-rice system (Seck et al., 2010). 406 SSA rice production is generally profitable and competitive in irrigated cultivations compared to 407 imported rice. Considering these encouraging results, SSA countries increased the investment in 408 constructing new irrigation systems (Seck et al., 2010). Irrigation of rice cultivations allowed 409 farmers to obtain very high yields (3-4 times higher than rainfed rice) and increased the harvests’ 410 intensity (Seck et al., 2010). Unfortunately, despite having higher yields, these crop systems tend 411 to be more susceptible to several pests and diseases, such as the rice yellow mottle virus, with 412 high temperatures (which are predicted to increase worldwide by the IPCC) positively 413 influencing most of them (Haq et al., 2010). 
414 In this context, we report some key results in which both climate and LULC current and future

415 scenarios heavily influence rice and pulla group co-occurrence. Indeed, our current predictions

416 show that the climatic suitability in the current scenario for rice crops is mainly found in two

417 districts, Western and Eastern Africa, being in accordance with Arouna et al. (2021). The former

418 shows high suitability for the pulla group, while the latter is suitable to this pest only in its

419 northern part, posing at-risk rice crops in both cases. Madagascar rice cultivations are also highly

420 susceptible to pulla group attacks. This susceptibility condition is predicted to worsen in the

421 future. Despite peaking in 2030 with the Mid-High (pulla-rice) class, the increase of the crucial

422 suitability classes (Mid-Mid, Mid-High, High-Mid, High-High) appears to stabilize within a

423 range between $+25 \%$ and $+30 \%$ in the SSP 2.45. Conversely, in the SSP 3.70, the suitable area of

424 these suitability classes is predicted to increase from 2030 until 2070, sometimes with high peaks

425 (Mid-Mid class, 2070).

426 These future highly suitable co-occurrences are also consistent with the future high connectivity

427 found among pulla group populations and rice patches, which is predicted to allow the pest 428 (bearing the RYMV) to infest the rice cultivations. Even though this virus can be transmitted

429 through contact by many mechanisms (Abo et al., 2000; Sarra et al., 2004; Traore et al., 2009),

430 the presence of beetles is assumed to support long-distance transmission (Fargette et al., 2006).

431 As further evidence, Banwo et al. (2001) found that even only 4 individuals of pulla group 432 determine the $80 \%$ of probability of RYMV infection, with a corresponding high yield loss 433 (Asante et al., 2020)

434 This is reflected by the rice production loss analyses (heatmaps), in which we find some countries 435 to suffer high losses, with the greatest predicted for Liberia and Sierra Leone. Despite this data, 436 these countries are reported to suffer less economic damage due to their cropping systems 437 (uplands rice crops), which are less susceptible to pulla group attack (Mogga et al., 2012; 438 Oludare et al., 2016; Suvi, Shimelis \& Laing, 2019). In fact, according to Oludare et al. (2016), 
439 uplands crops can resist RYMV attack better than lowland and irrigated croplands, which are

440 instead widely used in Central Africa Republic, Madagascar, and Guinea. In fact, the economic

441 analysis highlights critical issues regarding these countries in all future scenarios considered. A

442 few exceptions where a positive trend in the rice production loss/GDP ratio is predicted (Central

443 African Republic and Democratic Republic of Congo) are probably due to the lesser influence of

444 pulla group on the crops of these two countries. This is a result of the lower PAI values found,

445 which are in turn caused by a local decrease of suitability due to climate and land-use change.

\section{Conclusion}

448 The ongoing climate and land-use changes are proven to be detrimental to many processes, 449 especially in terms of human-nature interactions. Among these, agricultural practices standing 450 their foundations on the equilibria of plant-pest relationships are predicted to be particularly 451 threatened in the future, with severe economic losses, as reported in our research.

452 The use of combined ecological modelling, GIS analyses and connectivity estimates, summarized 453 in the Pest Aggression Index and presented in this work, is applicable in any plant/pest context, 454 even where few spatial data (e.g. occurrence-only and environmental predictors' datasets) is 455 available.

456 Considering the explicit spatial reference, this approach could target specific actions and future 457 landscape management, such as careful land-use planning to maintain biodiversity and focus on 458 economic investments.

460 Acknowledgements

461 This work was supported by the A.I.M. Project-PON R \& I 2014-2020 No. 1870582. All 462 authors declare no conflict of interest regarding the publication of this article. 463 


\section{References}

467

Abo ME, Alegbejo MD, Sy AA, Misari SM. 2000. An overview of the mode of transmission, host plants and methods of detection of rice yellow mottle virus. Journal of sustainable Agriculture 17:19-36.

Anantharaman R, Hall K, Shah VB, Edelman A. 2020. Circuitscape in Julia: High Performance Connectivity Modelling to Support Conservation Decisions. Proceedings of the JuliaCon Conferences 1:58. DOI: 10.21105/jcon.00058.

Arouna A, Fatognon IA, Saito K, Futakuchi K. 2021. Moving toward rice self-sufficiency in subSaharan Africa by 2030: Lessons learned from 10 years of the Coalition for African Rice Development. World Development Perspectives 21:100291.

Asante MD, Amadu B, Traore VSE, Oppong A, Adebayo MA, Aculey P, Marfo EA, Kang K-H. 2020. Assessment of Korean rice lines for their reaction to rice yellow mottle virus in Ghana. Heliyon 6:e05551.

Bakker W. 1971. Three new beetle vectors of rice yellow mottle virus in Kenya. Netherlands journal of plant pathology 77:201-206.

Balasubramanian V, Sie M, Hijmans RJ, Otsuka K. 2007. Increasing rice production in subSaharan Africa: challenges and opportunities. Advances in agronomy 94:55-133.

Banwo OO, Makundi RH, Abdallah RS, Mbapila JC. 2001. Newly recorded species of Chaetocnema, vector of rice yellow mottle virus in Tanzania.

Bezanson J, Edelman A, Karpinski S, Shah VB. 2017. Julia: A fresh approach to numerical computing. SIAM review 59:65-98.

Biondi M. 2001. Revision of the species of Chaetocnema from Madagascar (Coleoptera: Chrysomelidae: Alticinae). European Journal of Entomology 98:233-248. 
489 Biondi M. 2002. Checklist of Afrotropical species of the genus Chaetocnema Stephens

490 (Coleoptera: Chrysomelidae: Alticinae): synonymies and geographical distribution.

$491 \quad$ African entomology 10:265-284.

492 Biondi M, D’Alessandro P. 2006a. Biogeographical analysis of the flea beetle genus

493 Chaetocnema in the Afrotropical Region: distribution patterns and areas of endemism.

$494 \quad$ Journal of Biogeography 33:720-730.

495 Biondi M, D’Alessandro P. 2006b. A revision of the South African Chaetocnema gahani

496 speciesgroup, with descriptions of four new flea beetle species (Coleoptera:

497

Chrysomelidae). In: Annales de la Société entomologique de France. Taylor \& Francis, 183-196.

499 Biondi M, D’Alessandro P. 2008. Revision of the Chaetocnema pulla species-group from the

500 Afrotropical region with description of a new species from Central Africa (Coleoptera,

501 Chrysomelidae). Research on Chrysomelidae 1:265-285.

502 Biondi M, D’Alessandro P. 2018. Two new species of Chaetocnema Stephens from South Africa

503 (Coleoptera: Chrysomelidae, Galerucinae, Alticini). Fragmenta entomologica 50:11-18.

504 Biondi M, Urbani F, D’Alessandro P. 2015. Relationships between the geographic distribution of

505 phytophagous insects and different types of vegetation: A case study of the flea beetle

506 genus Chaetocnema (Coleoptera: Chrysomelidae) in the Afrotropical region. European

$507 \quad$ Journal of Entomology 112.

508 Boucher O, Servonnat J, Albright AL, Aumont O, Balkanski Y, Bastrikov V, Bekki S, Bonnet R,

509 Bony S, Bopp L. 2020. Presentation and evaluation of the IPSL CM6A LR climate

$510 \quad$ model. Journal of Advances in Modeling Earth Systems 12:e2019MS002010.

511 Boyce MS, Vernier PR, Nielsen SE, Schmiegelow FK. 2002. Evaluating resource selection

$512 \quad$ functions. Ecological modelling 157:281-300. 
513 Brown JL, Bennett JR, French CM. 2017. SDMtoolbox 2.0: the next generation Python-based

514 GIS toolkit for landscape genetic, biogeographic and species distribution model analyses.

$515 \quad$ PeerJ 5:e4095.

516 Brunetti M, Magoga G, Iannella M, Biondi M, Montagna M. 2019. Phylogeography and species

517 distribution modelling of Cryptocephalus barii (Coleoptera: Chrysomelidae): is this

$518 \quad$ alpine endemic species close to extinction? ZooKeys 856:3.

519 Burkhard B, Kandziora M, Hou Y, Müller F. 2014. Ecosystem service potentials, flows and

520 demands-concepts for spatial localisation, indication and quantification. Landscape

$521 \quad$ online $34: 1-32$.

522 Carpenter AJ. 1978. The history of rice in Africa. In: Rice in Africa. Proceedings of a conference

523 held at the International Institute of Tropical Agriculture Ibadan, Nigeria, 7-11 March

524 1977. Academic Press Inc.(London) Ltd., 3-10.

525 Carpenter SR, DeFries R, Dietz T, Mooney HA, Polasky S, Reid WV, Scholes RJ. 2006.

526 Millennium ecosystem assessment: research needs.

527 Chauhan BS, Jabran K, Mahajan G. 2017. Rice production worldwide.

528 Console G, Iannella M, Cerasoli F, D’Alessandro P, Biondi M. 2020. A European perspective of

529 the conservation status of the threatened meadow viper Vipera ursinii (BONAPARTE,

530 1835) (Reptilia, Viperidae). Wildlife Biology 2:1-12. DOI: 10.2981/wlb.00604.

531 De Simone W, Iannella M, D’Alessandro P, Biondi M. 2020. Assessing influence in biofuel

532 production and ecosystem services when environmental changes affect plant-pest

533 relationships. Gcb Bioenergy 12:864-877. DOI: 10.1111/gcbb.12727.

534 deGraft Johnson M, Suzuki A, Sakurai T, Otsuka K. 2014. On the transferability of the Asian

535 rice green revolution to rainfed areas in sub Saharan Africa: an assessment of technology

536 intervention in Northern Ghana. Agricultural Economics 45:555-570. 
537 Dellicour S, Vrancken B, Trovão NS, Fargette D, Lemey P. 2018. On the importance of negative 538 controls in viral landscape phylogeography. Virus Evolution 4:vey023.

539 Di Cola V, Broennimann O, Petitpierre B, Breiner FT, D’Amen M, Randin C, Engler R, Pottier J, 540 Pio D, Dubuis A. 2017. ecospat: An R package to support spatial analyses and modeling $541 \quad$ of species niches and distributions. Ecography 40:774-787.

542 Dormann CF. 2007. Effects of incorporating spatial autocorrelation into the analysis of species 543 distribution data. Global Ecology and Biogeography 16:129-138.

544 Elith J, H Graham C, P Anderson R, Dudík M, Ferrier S, Guisan A, J Hijmans R, Huettmann F, R Leathwick J, Lehmann A, Li J, G Lohmann L, A Loiselle B, Manion G, Moritz C, Nakamura M, Nakazawa Y, McC Overton J, Townsend Peterson A, J Phillips S, Richardson K, Schachetti-Pereira R, Schapire RE, Soberòn J, Williams S, S Wisz M, E Zimmermann N, Araújo M. 2006. Novel methods improve prediction of species’ distributions from occurrence data. Ecography 29:129-151.

Elith J, Leathwick JR. 2009. Species distribution models: ecological explanation and prediction across space and time. Annual Review of Ecology, Evolution, and Systematics 40:677697.

553 ESRI. 2010. ArcMap 10.0. ESRI, Redlands, California.

554 FAO. 2016. FAOSTAT Crops production database.

555 FAO F. 2017. The future of food and agriculture-Trends and challenges. Annual Report.

556 Fargette D, Konate G, Fauquet C, Muller E, Peterschmitt M, Thresh JM. 2006. Molecular ecology and emergence of tropical plant viruses. Annu. Rev. Phytopathol. 44:235-260.

558 Fick SE, Hijmans RJ. 2017. WorldClim 2: new 1 km spatial resolution climate surfaces for global land areas. International journal of climatology 37:4302-4315.

560 Fricko O, Havlik P, Rogelj J, Klimont Z, Gusti M, Johnson N, Kolp P, Strubegger M, Valin H, 561 Amann M. 2017. The marker quantification of the Shared Socioeconomic Pathway 2: A 

267.

564 Fujimori S, Hasegawa T, Masui T, Takahashi K, Herran DS, Dai H, Hijioka Y, Kainuma M.

565 2017. SSP3: AIM implementation of shared socioeconomic pathways. Global

$566 \quad$ Environmental Change 42:268-283.

567 Griscom BW, Goodman RC, Burivalova Z, Putz FE. 2018. Carbon and biodiversity impacts of 568 intensive versus extensive tropical forestry. Conservation Letters 11:e12362.

569 Guisan A, Thuiller W, Zimmermann NE. 2017. Habitat suitability and distribution models: with $570 \quad$ applications in R. Cambridge University Press.

571 Haq M, Mia MT, Rabbi MF, Ali MA. 2010. Incidence and severity of rice diseases and insect pests in relation to climate change. In: Climate change and food security in South Asia.

574 Heinrichs EA. 2004. Rice-feeding insects and selected natural enemies in West Africa: biology, 575 ecology, identification. Int. Rice Res. Inst.

576 Hirzel AH, Le Lay G, Helfer V, Randin C, Guisan A. 2006. Evaluating the ability of habitat 577 suitability models to predict species presences. Ecological modelling 199:142-152.

578 Hubert J, Lyimo HJ, Luzi-Kihupi A. 2017. Geographical variation, distribution and diversity of 579 Rice yellow mottle virus phylotypes in Tanzania. American Journal of Plant Sciences $580 \quad 8: 1264$.

581 Iannella M, Cerasoli F, Biondi M. 2017. Unraveling climate influences on the distribution of the $582 \quad$ parapatric newts Lissotriton vulgaris meridionalis and L. italicus. Frontiers in Zoology $583 \quad 14: 55$

584 Iannella M, Cerasoli F, D’Alessandro P, Console G, Biondi M. 2018. Coupling GIS spatial 585 analysis and Ensemble Niche Modelling to investigate climate change-related threats to 
the Sicilian pond turtle Emys trinacris, an endangered species from the Mediterranean. PeerJ 6:e4969.

588 Iannella M, De Simone W, D’Alessandro P, Console G, Biondi M. 2019. Investigating the Current and Future Co-Occurrence of Ambrosia artemisiifolia and Ophraella communa in Europe through Ecological Modelling and Remote Sensing Data Analysis. International journal of environmental research and public health 16:3416.

592

Iannella M, Liberatore L, Biondi M. 2016. The effects of a sudden urbanization on micromammal communities: a case study of post-earthquake L’Aquila (Abruzzi Region, Italy). Italian Journal of Zoology 83:255-262.

Jayne T, Rashid S. 2013. Input subsidy programs (ISPs) in Sub-Saharan Africa (SSA). Agricultural Economics 44:545-734.

Jones PM, Mande S, Aluko K. 1997. Diversity and potential of Oryza glaberrima Steud in upland rice breeding. Japanese Journal of Breeding 47:395-398.

Koffi G. 1980. Etude de la Variabilite des Riz Africains en Vue. leur Utilisation en SM ection.

Kouassi NK, N’guessan P, Albar L, Fauquet CM, Brugidou C. 2005. Distribution and characterization of Rice yellow mottle virus: a threat to African farmers. Plant disease 89:124-133.

Koudamiloro A, Nwilene FE, Togola A, Akogbeto M. 2015. Insect vectors of rice yellow mottle virus. Journal of Insects 2015.

Mbow C, Rosenzweig C, Barioni LG, Benton TG, Herrero M, Krishnapillai M, Waha K. 2019. Chapter 5: food security. IPCC Special Report on Climate Change and Land, online at https://www. ipcc. ch/site/assets/uploads.

McClure ML, Hansen AJ, Inman RM. 2016. Connecting models to movements: testing connectivity model predictions against empirical migration and dispersal data. Landscape 
611 McRae BH, Dickson BG, Keitt TH, Shah VB. 2008. Using circuit theory to model connectivity 612 in ecology, evolution, and conservation. Ecology 89:2712-2724.

613 McRae BH, Shah V, Edelman A. 2016. Circuitscape: modeling landscape connectivity to 614 promote conservation and human health. The Nature Conservancy 14.

615 Mogga ML, Lamo J, Asea G, Gibson P, Edema R. 2012. Reaction of rice cultivars to a virulent 616 rice yellow mottle virus strain in Uganda. African Crop Science Journal 20.

617 Naimi B. 2015. usdm: uncertainty analysis for species distribution models. R package version 618 1.1-15. R Documentation http://www. rdocu-mentation. org/packages/usdm.

619 Occdownload Gbif.Org. 2020. Occurrence Download. DOI: 10.15468/DL.CDZHHB.

620 Oludare A, Tossou HT, Kini K, Silué D. 2016. Diversity of Rice yellow mottle virus in Benin and Togo and Screening for Resistant Accessions. Journal of Phytopathology 164:924-

623 Oteng JW, Sant’Anna R, Van Tran D. 1999. Rice production in Africa: Current situation and 624 issues.

625 Phillips SJ, Anderson RP, Schapire RE. 2006. Maximum entropy modeling of species geographic 626 distributions. Ecological Modelling 190:231-259.

627 QGIS Development Team. 2021. QGIS Geographic Information System. QGIS Association.

628 R Core Team. 2016. R: A language and environment for statistical computing. R Foundation for 629 Statistical Computing, Vienna, Austria. URL http://www.R-project.org/.

630 Rakotomalala M, Vrancken B, Pinel-Galzi A, Ramavovololona P, Hébrard E, Randrianangaly JS, 631 Dellicour S, Lemey P, Fargette D. 2019. Comparing patterns and scales of plant virus 632 phylogeography: Rice yellow mottle virus in Madagascar and in continental Africa. Virus 633 evolution 5:vez023.

634 Riahi K, Van Vuuren DP, Kriegler E, Edmonds J, O’neill BC, Fujimori S, Bauer N, Calvin K, 635 Dellink R, Fricko O. 2017. The shared socioeconomic pathways and their energy, land 

Change 42:153-168.

638 Sarra S, Oevering P, Guindo S, Peters D. 2004. Wind mediated spread of Rice yellow mottle 639 virus (RYMV) in irrigated rice crops. Plant Pathology 53:148-153.

640 Seck PA, Tollens E, Wopereis MC, Diagne A, Bamba I. 2010. Rising trends and variability of 641 rice prices: Threats and opportunities for sub-Saharan Africa. Food Policy 35:403-411.

642 Sharp R, Tallis HT, Ricketts T, Guerry AD, Wood SA, Chaplin-Kramer R, Nelson E, Ennaanay 643 D, Wolny S, Olwero N. 2018. InVEST 3.7. 0. post17+ hbeb7e1912b14 User’s Guide. The $644 \quad$ Natural Capital Project.

645 Sillero N, Barbosa AM. 2020. Common mistakes in ecological niche models. International 646 Journal of Geographical Information Science:1-14. DOI:

$647 \quad 10.1080 / 13658816.2020 .1798968$.

648 Stralberg D, Matsuoka SM, Hamann A, Bayne EM, Sólymos P, Schmiegelow FKA, Wang X, 649 Cumming SG, Song SJ. 2015. Projecting boreal bird responses to climate change: the $650 \quad$ signal exceeds the noise. Ecological Applications 25:52-69.

651 Suvi WT, Shimelis H, Laing M. 2019. Breeding rice for rice yellow mottle virus resistance in 652 Sub-Saharan Africa: A review. Acta Agriculturae Scandinavica, Section B—Soil \& Plant $653 \quad$ Science 69:181-188.

654 Tatebe H, Ogura T, Nitta T, Komuro Y, Ogochi K, Takemura T, Sudo K, Sekiguchi M, Abe M, 655 Saito F. 2019. Description and basic evaluation of simulated mean state, internal 656 variability, and climate sensitivity in MIROC6. Geoscientific Model Development $657 \quad 12: 2727-2765$.

658 Traore O, Pinel-Galzi A, Sorho F, Sarra S, Rakotomalala M, Sangu E, Kanyeka Z, Séré Y, 659 Konaté G, Fargette D. 2009. A reassessment of the epidemiology of Rice yellow mottle 
660

virus following recent advances in field and molecular studies. Virus research 141:258-

661 267.

662 Trovão NS, Baele G, Vrancken B, Bielejec F, Suchard MA, Fargette D, Lemey P. 2015. Host

663 ecology determines the dispersal patterns of a plant virus. Virus evolution 1.

664 Waskom ML. 2021. Seaborn: statistical data visualization. Journal of Open Source Software

$665 \quad 6: 3021$.

666 WFP VAM. 2017.

667 Wopereis MC, Johnson DE, Ahmadi N, Tollens E, Jalloh A. 2013. Realizing Africa's rice

668 promise. CABI.

669 Wu T, Lu Y, Fang Y, Xin X, Li L, Li W, Jie W, Zhang J, Liu Y, Zhang L. 2019. The Beijing

670 Climate Center climate system model (BCC-CSM): The main progress from CMIP5 to

671 CMIP6. Geoscientific Model Development 12:1573-1600.

672 Yu Q, You L, Wood-Sichra U, Ru Y, Joglekar AK, Fritz S, Xiong W, Lu M, Wu W, Yang P.

673 2020. A cultivated planet in 2010-Part 2: the global gridded agricultural-production maps.

$674 \quad$ Earth System Science Data 12:3545-3572.

675

676

677

678 Figure legends

679 Fig. 1. The rationale of the workflow used to calculate the Mean Corridor Magnitude, with the 680 total landscape connectivity among Chaetocnema pulla populations and rice cultivations (A) 681 being discretized in single corridors (B) and converted into unique connectivity values, from $C$. 682 pulla populations to rice cultivations, based on the mean connectivity value such obtained (Mean 683 Corridor Magnitude) (C). 
684 Fig. 2. Distribution of Chaetocnema pulla species group and rice cultivations in sub-Saharan 685 Africa.

686 Fig. 3. The current asset of suitability classes’ pairs between Chaetocnema pulla species group 687 and rice cultivations.

688 Fig. 4. Future predicted assets of suitability classes’ pairs between Chaetocnema pulla species 689 group and rice cultivations for all considered scenarios. (A) SSP2_4.5 2030, (B) SSP2_4.5 2050, 690 (C) SSP2_4.5 2070, (D) SSP3_7.0 2030,(E) SSP3_7.0 2050 and (F) SSP3_7.0 2070.

691 Fig. 5. Heatmap of rice production loss (ton/ha * year) expressed as a percentage for each sub692 Saharan country (for all future scenarios); stacked-bars of rice production loss in relation to GDP 693 in USD (expressed in \%) for each sub-Saharan country (all future scenarios considered). (A) 694 SSP_2.45 scenario; (B) SSP_3.70 scenario.

695

696

697 

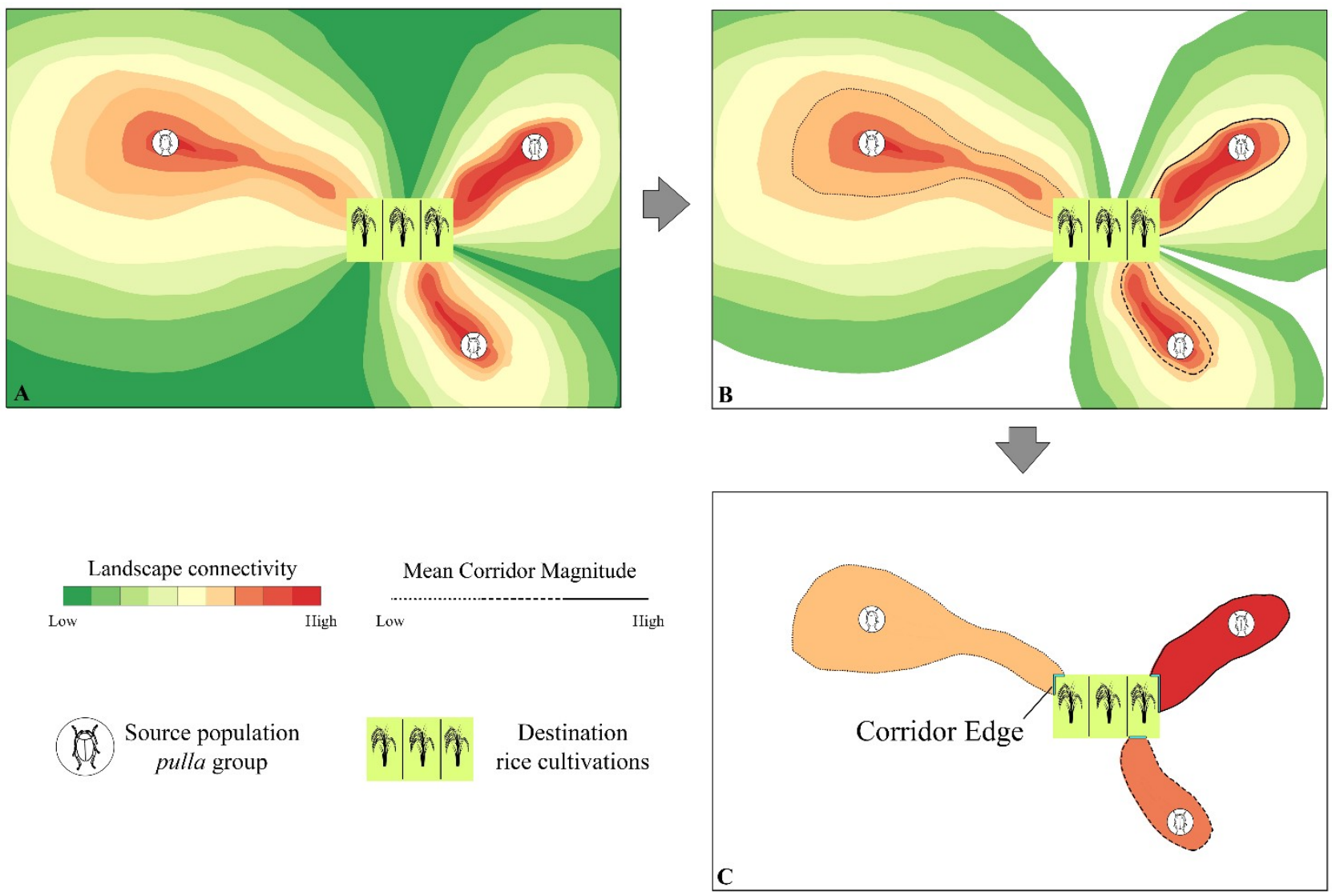

699 Fig. 1 


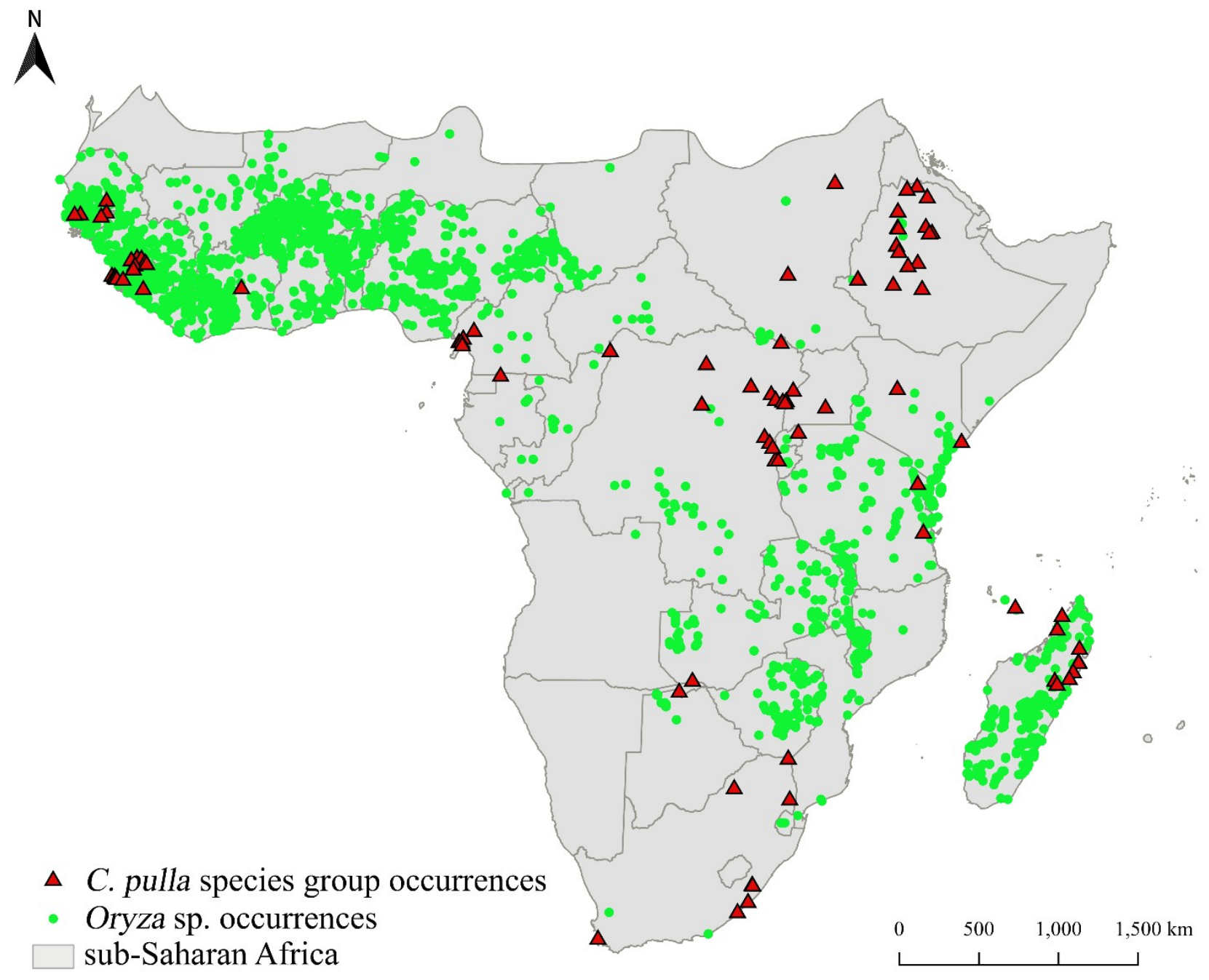

Fig. 2 


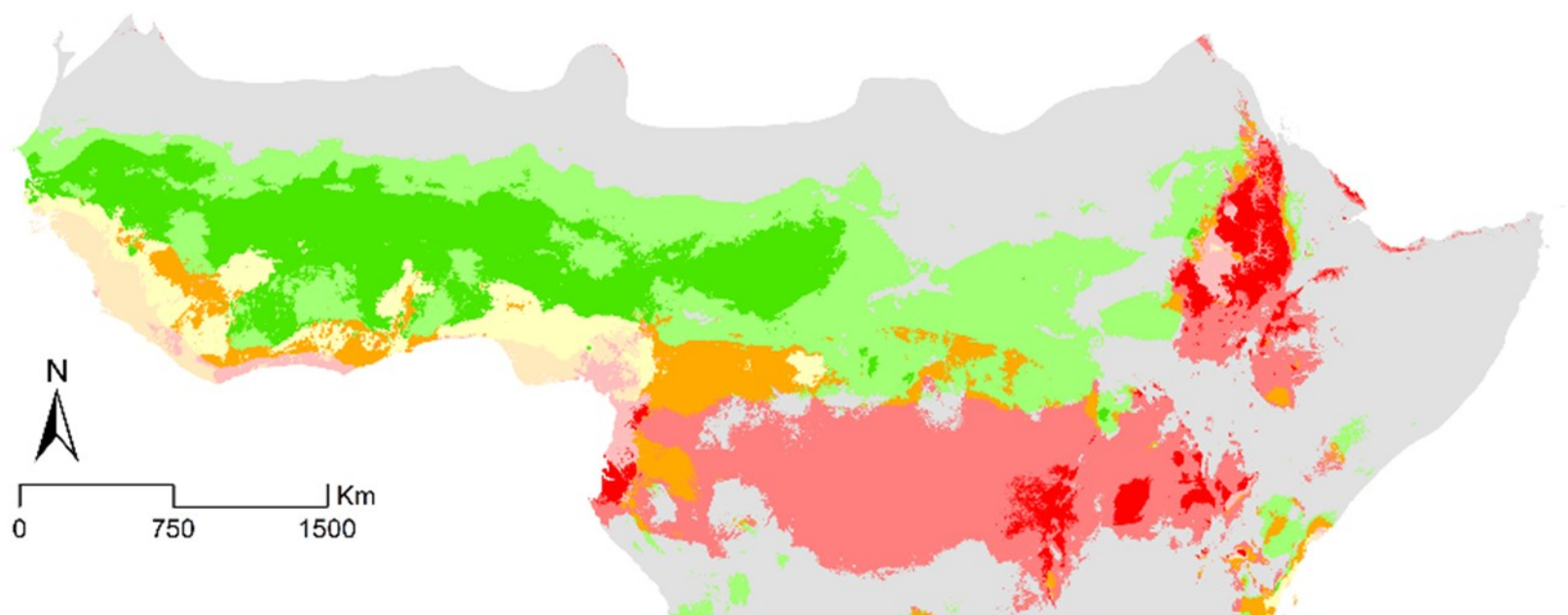

Suitability classes

C. pulla-Oryza

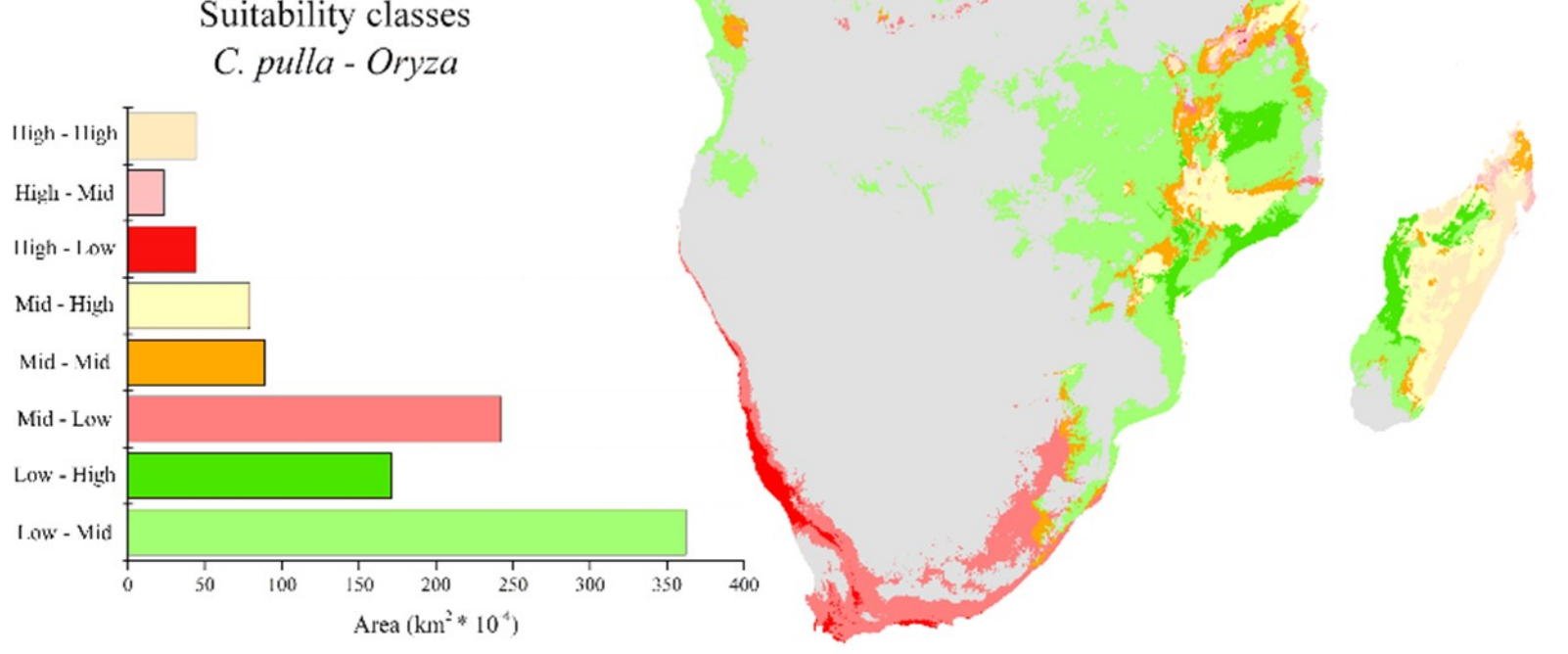

703 Fig. 3

704

705 
A

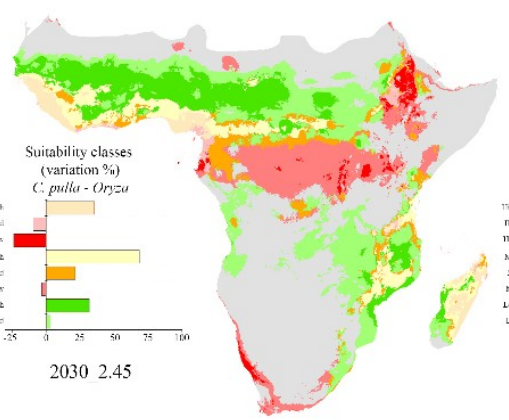

D

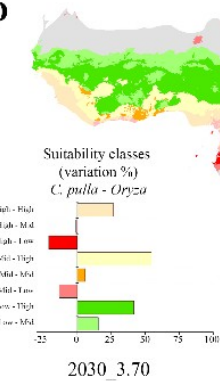

B

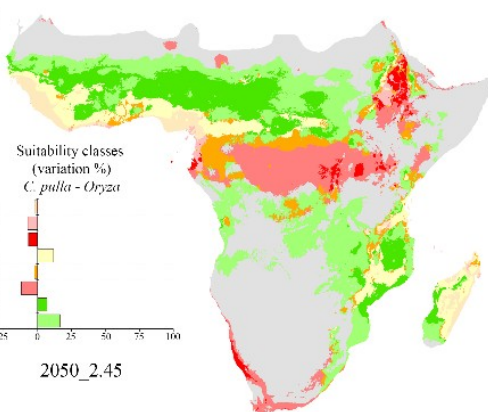

$\mathbf{E}$

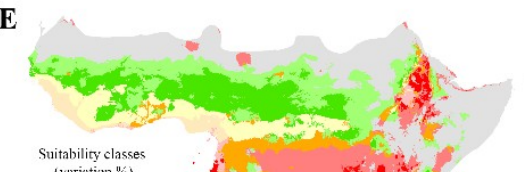

$\mathbf{F}$
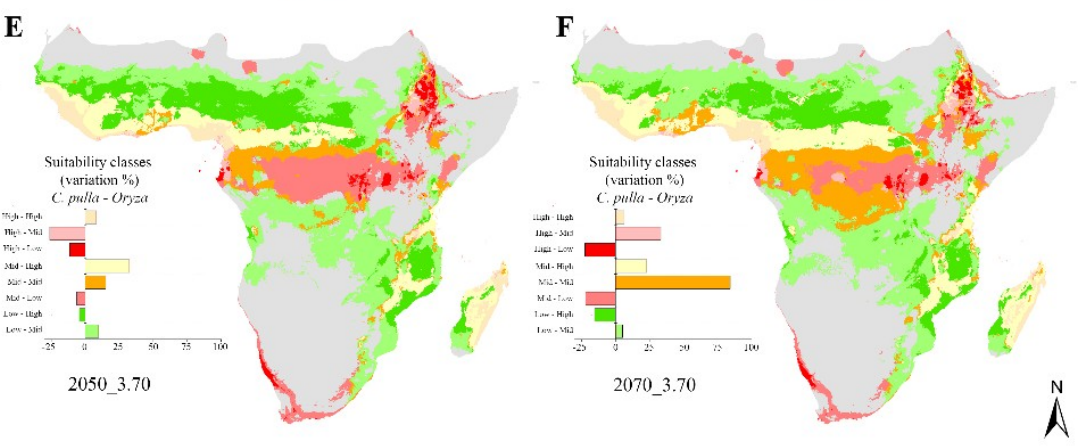

706

707

Fig. 4

708 
A
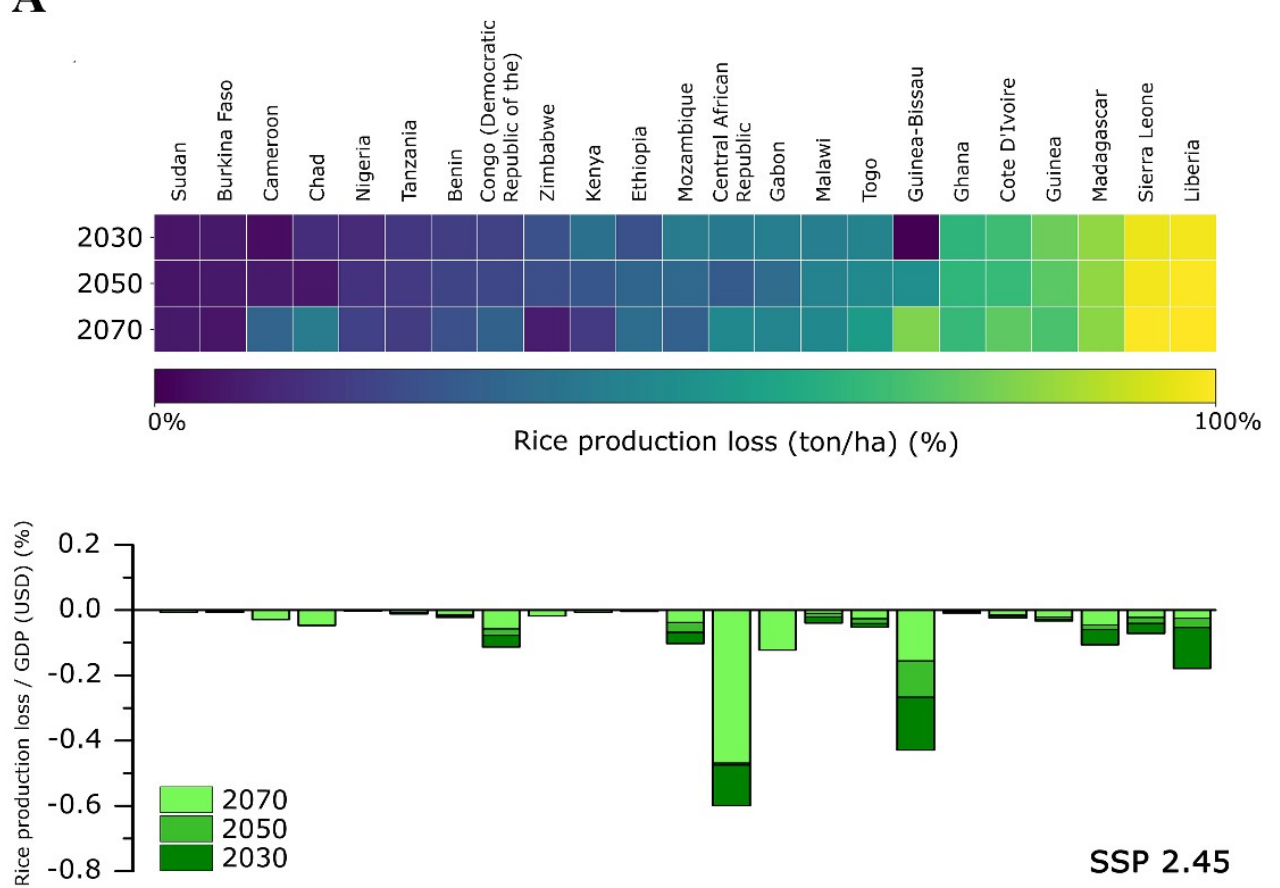

B
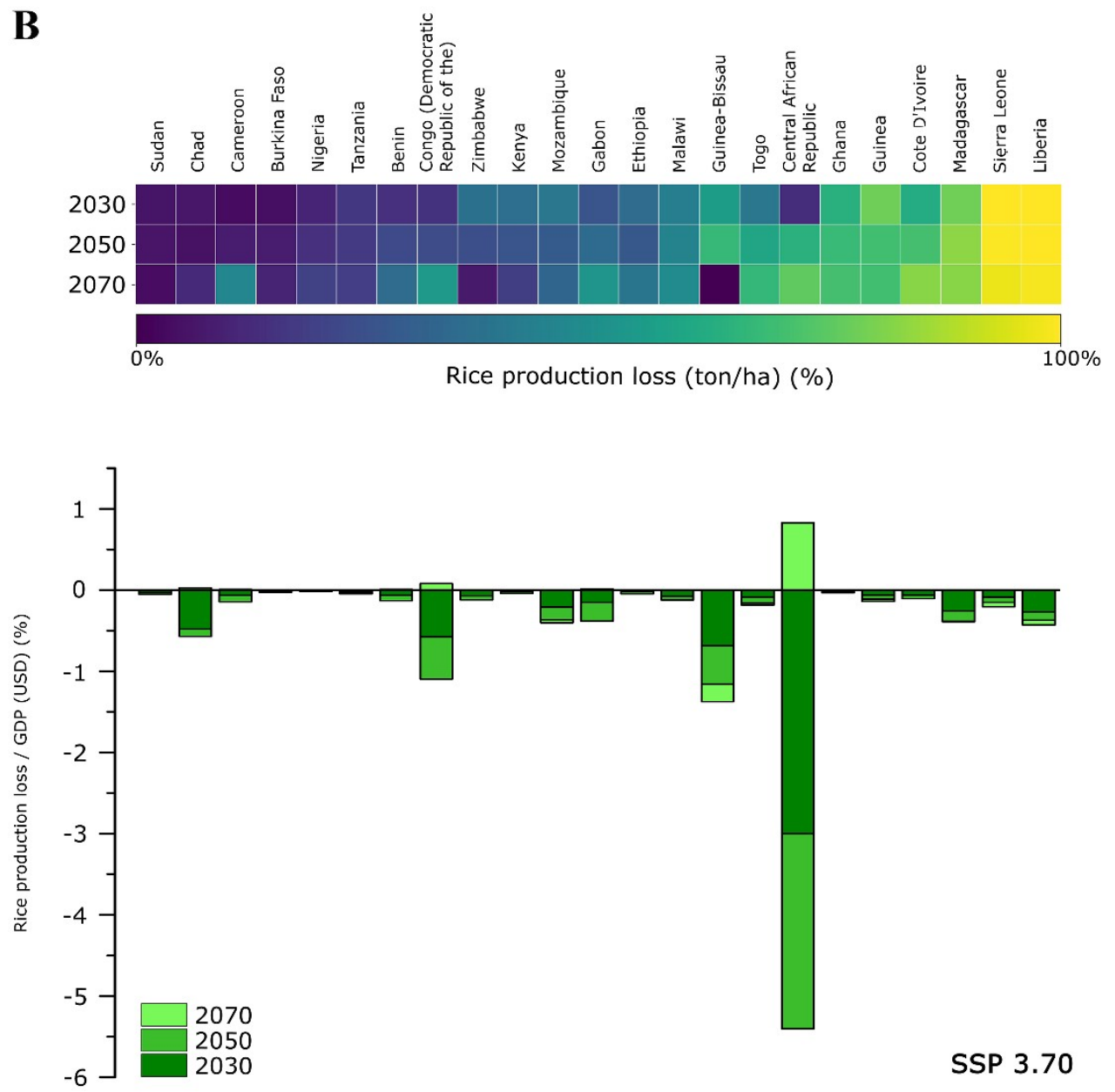
710 Fig. 5 


\section{Figure 1}

Mean Corridor Magnitude workflow.

The rationale of the workflow used to calculate the Mean Corridor Magnitude, with the total landscape connectivity among Chaetocnema pulla populations and rice cultivations (a) being discretized in single corridors (b) and converted into unique connectivity values, from C. pulla populations to rice cultivations, based on the mean connectivity value such obtained (Mean Corridor Magnitude) (c).
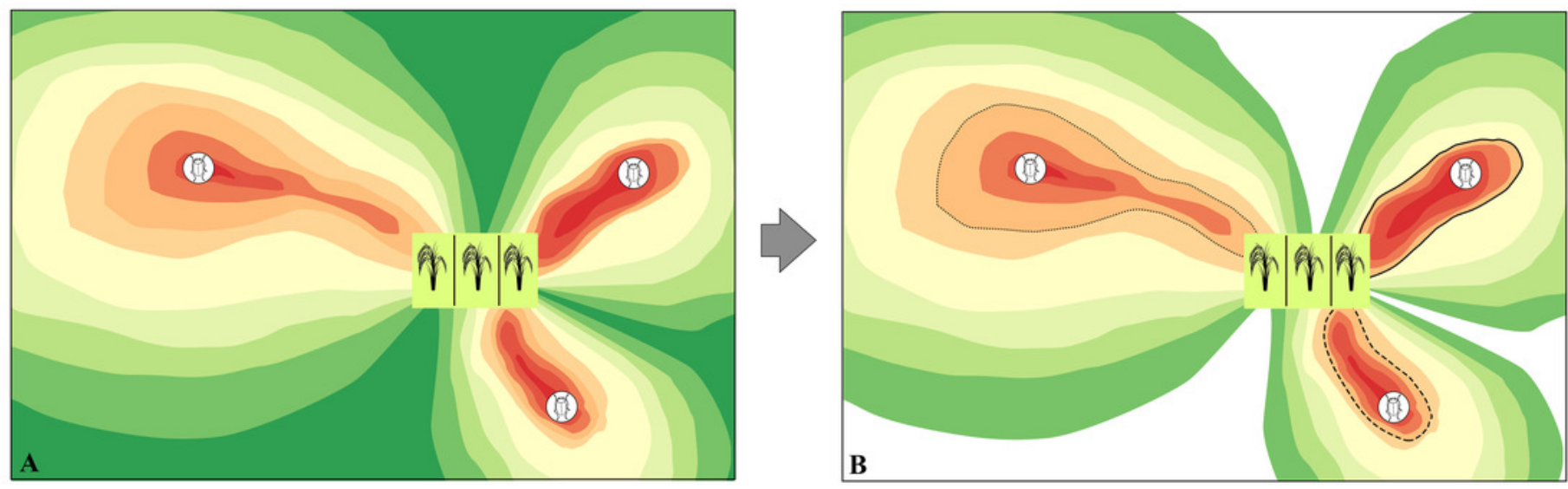
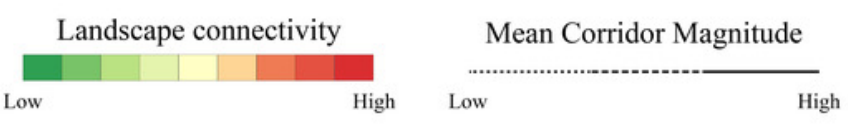

Source population pulla group

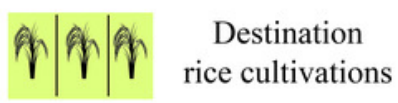

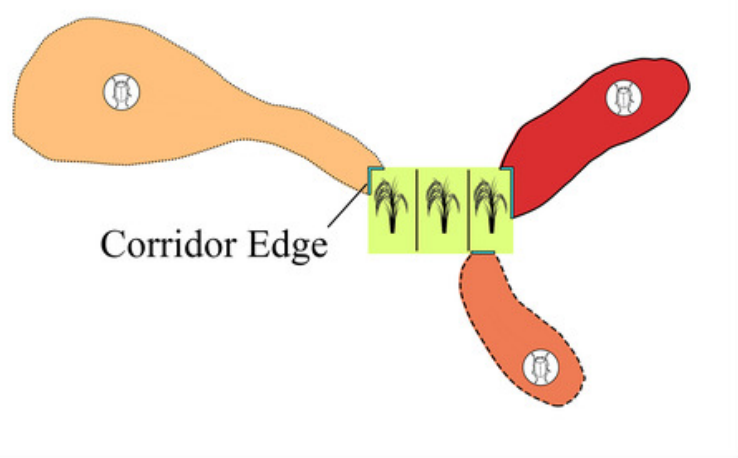


Figure 2

Distribution of two target taxa.

Distribution of Chaetocnema pulla species group and rice cultivations in sub-Saharan Africa.

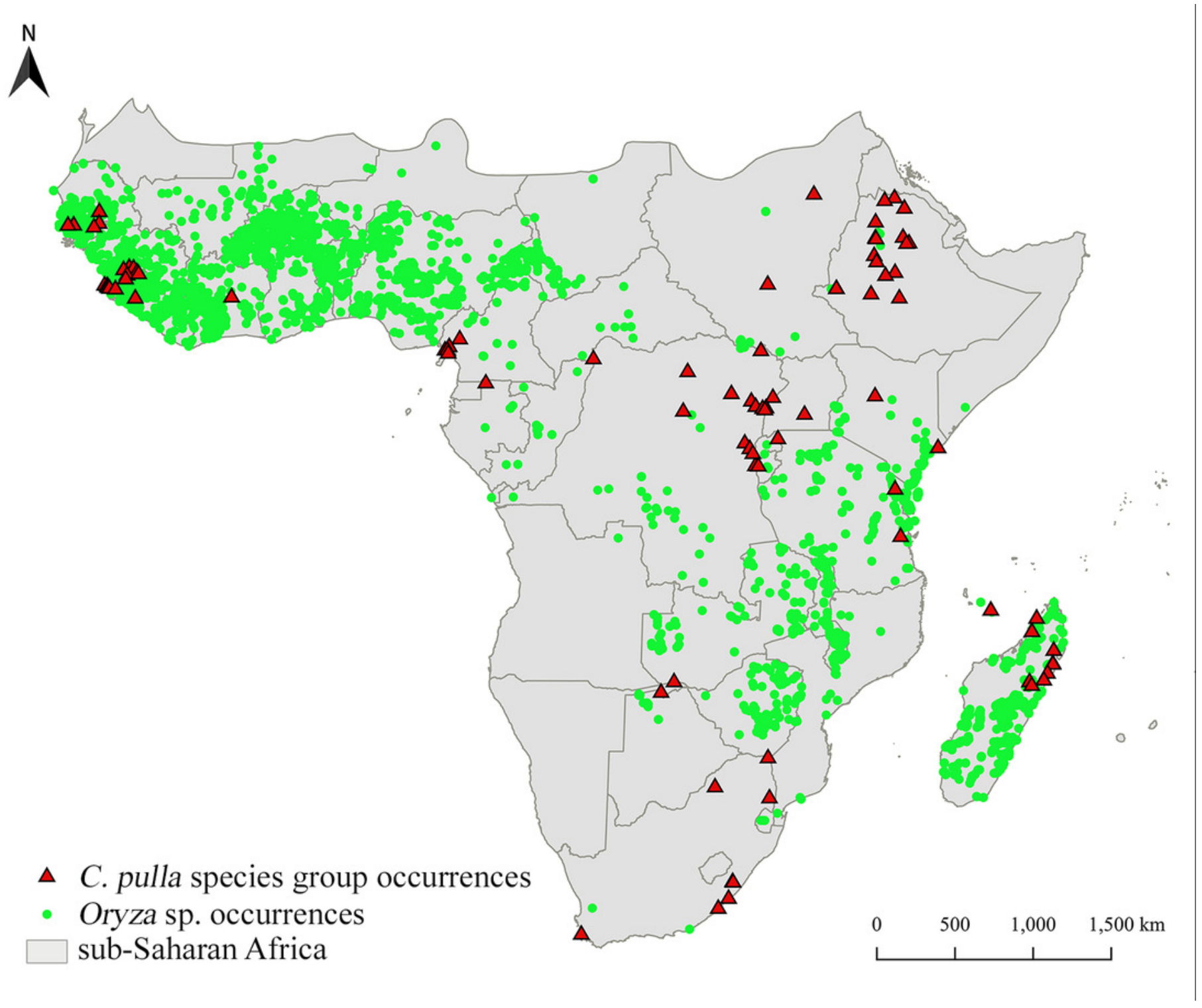




\section{Figure 3}

Current suitability classes' combinations

The current asset of suitability classes' pairs between Chaetocnema pulla species group and rice cultivations.

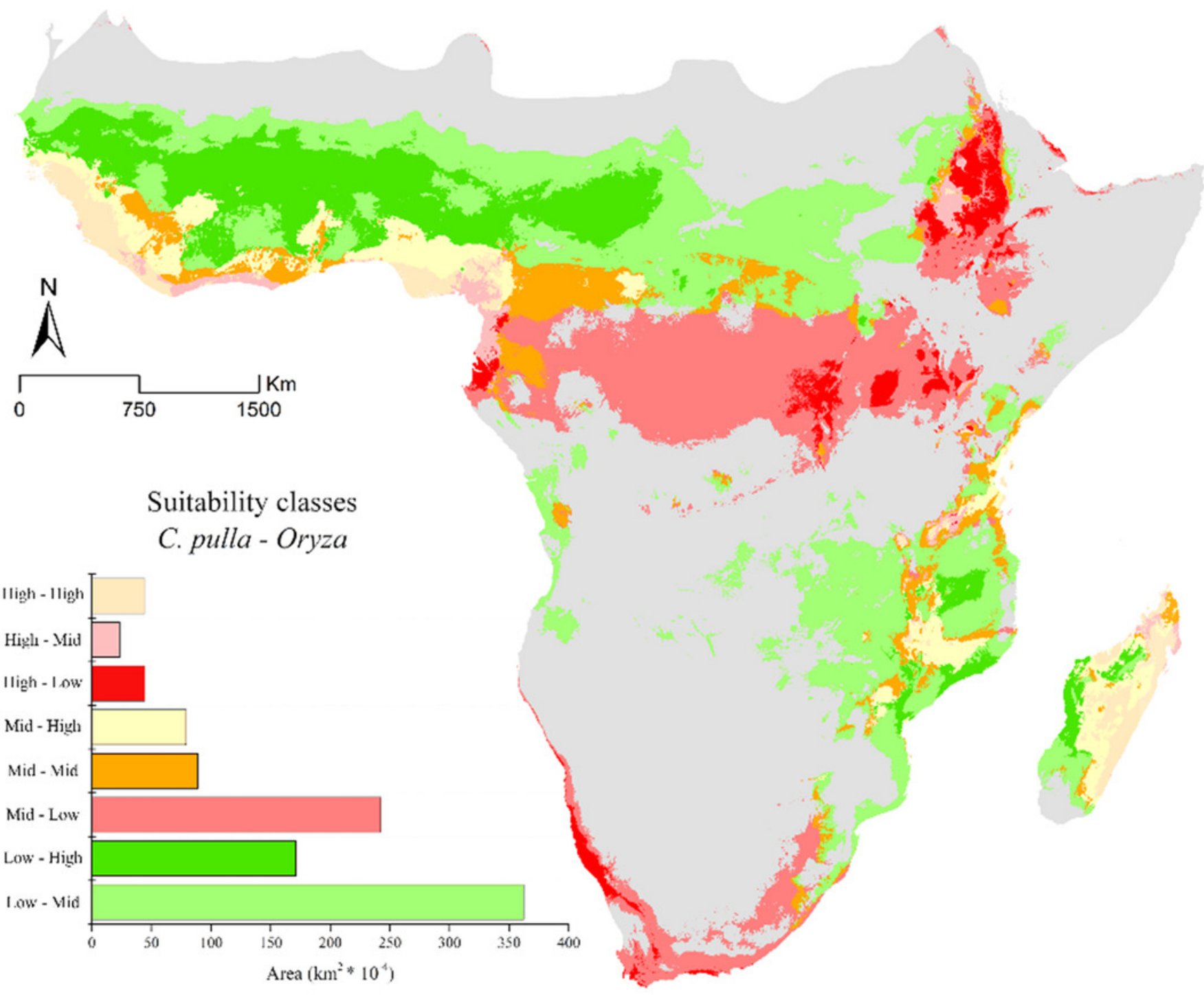


Figure 4

Future suitability classes' combinations

Future predicted assets of suitability classes' pairs between Chaetocnema pulla species group and rice cultivations for all considered scenarios.

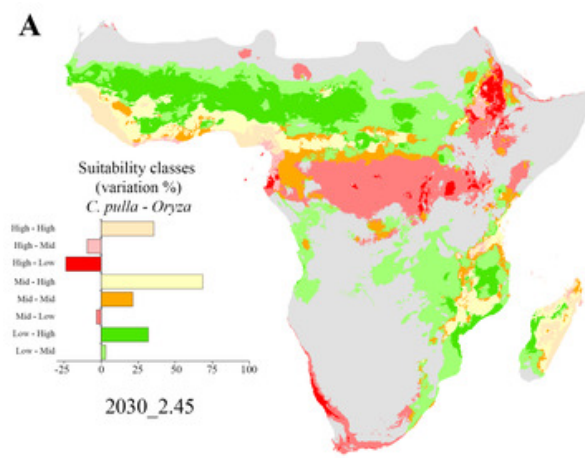

D

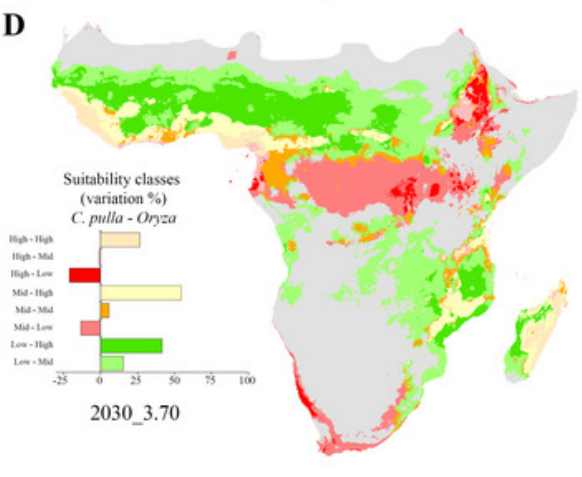

Low - Mid
B

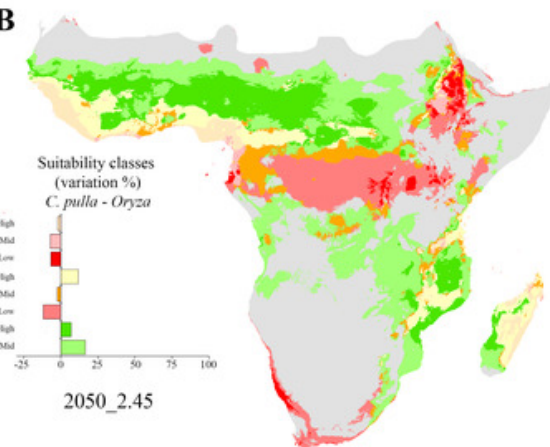

$\mathbf{E}$

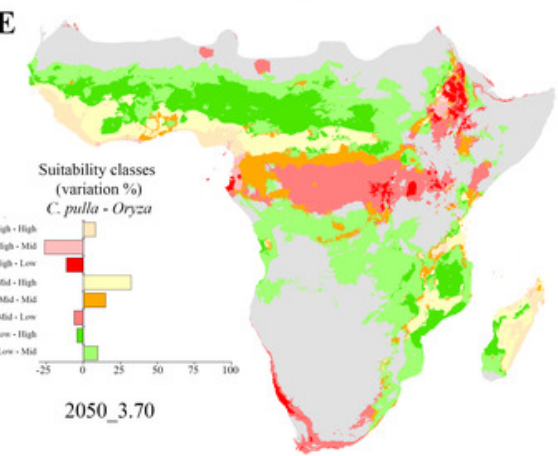

Mid - High
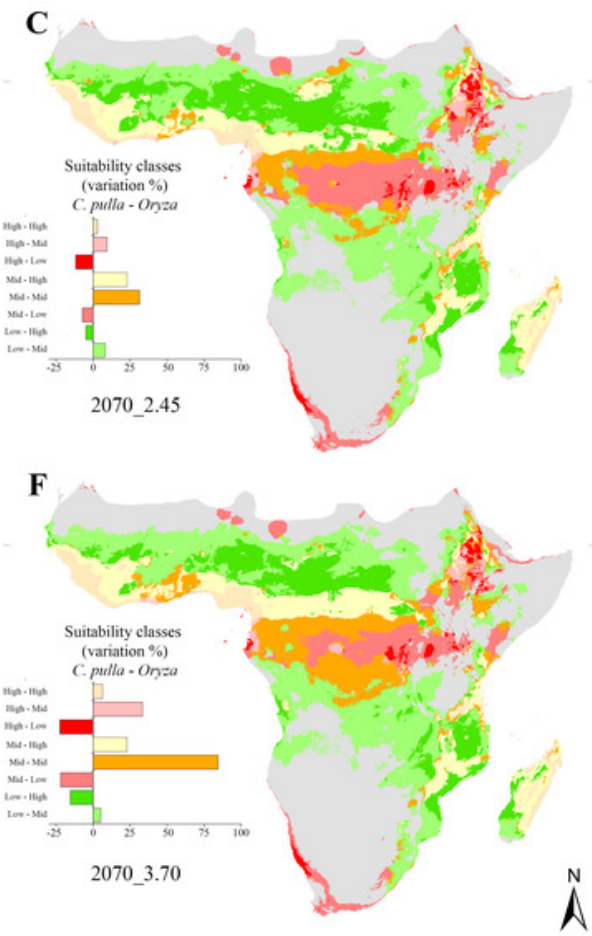

High - Low

High-Mid High-High 


\section{Figure 5}

Losses in rice production and gross domestic product (GDP).

Heatmap of rice production loss (ton/ha * year) expressed as a percentage for each sub-

Saharan country (for all future scenarios); stacked-bars of rice production loss in relation to GDP in USD (expressed in \%) for each sub-Saharan country (all future scenarios considered).

(a) SSP_2.45 scenario; (b) SSP_3.70 scenario. 
A
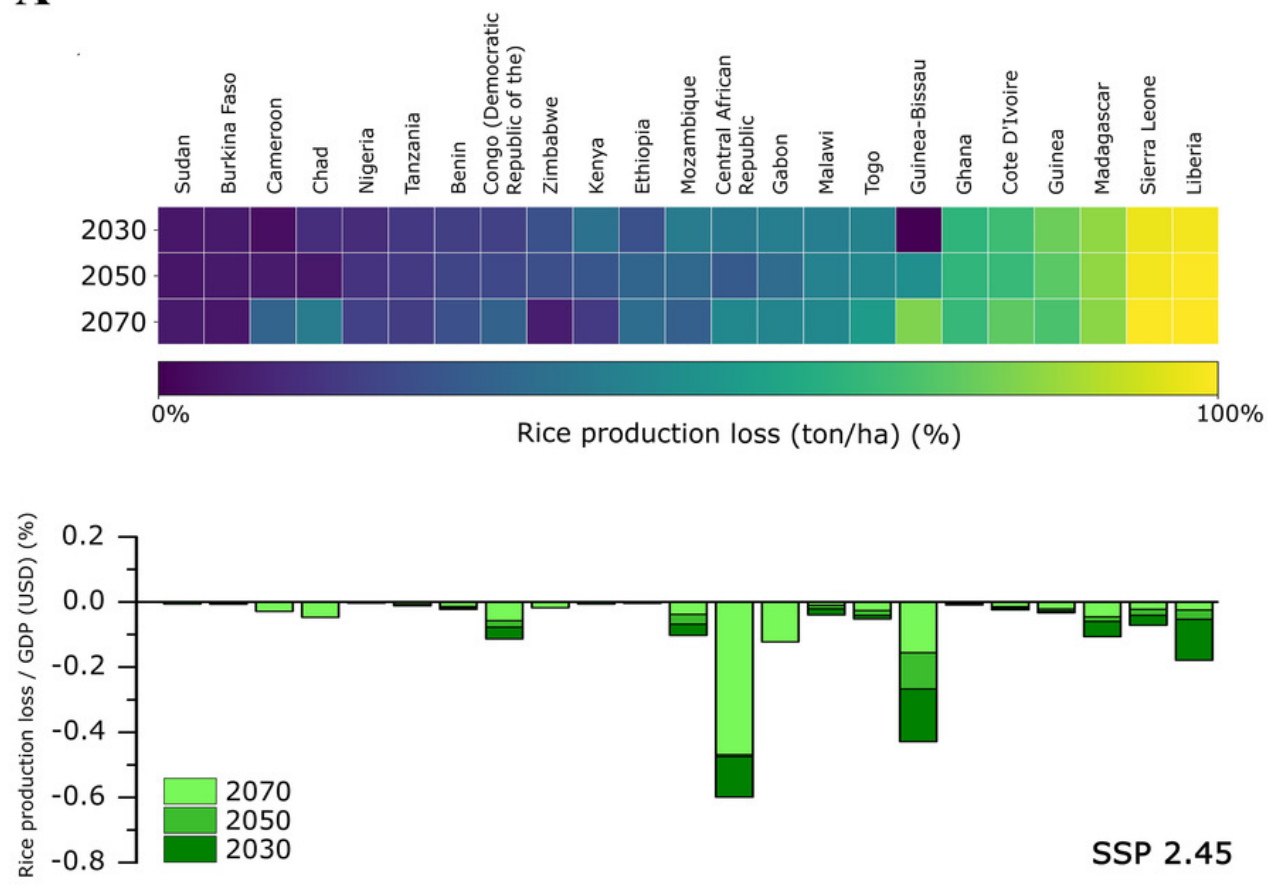

B
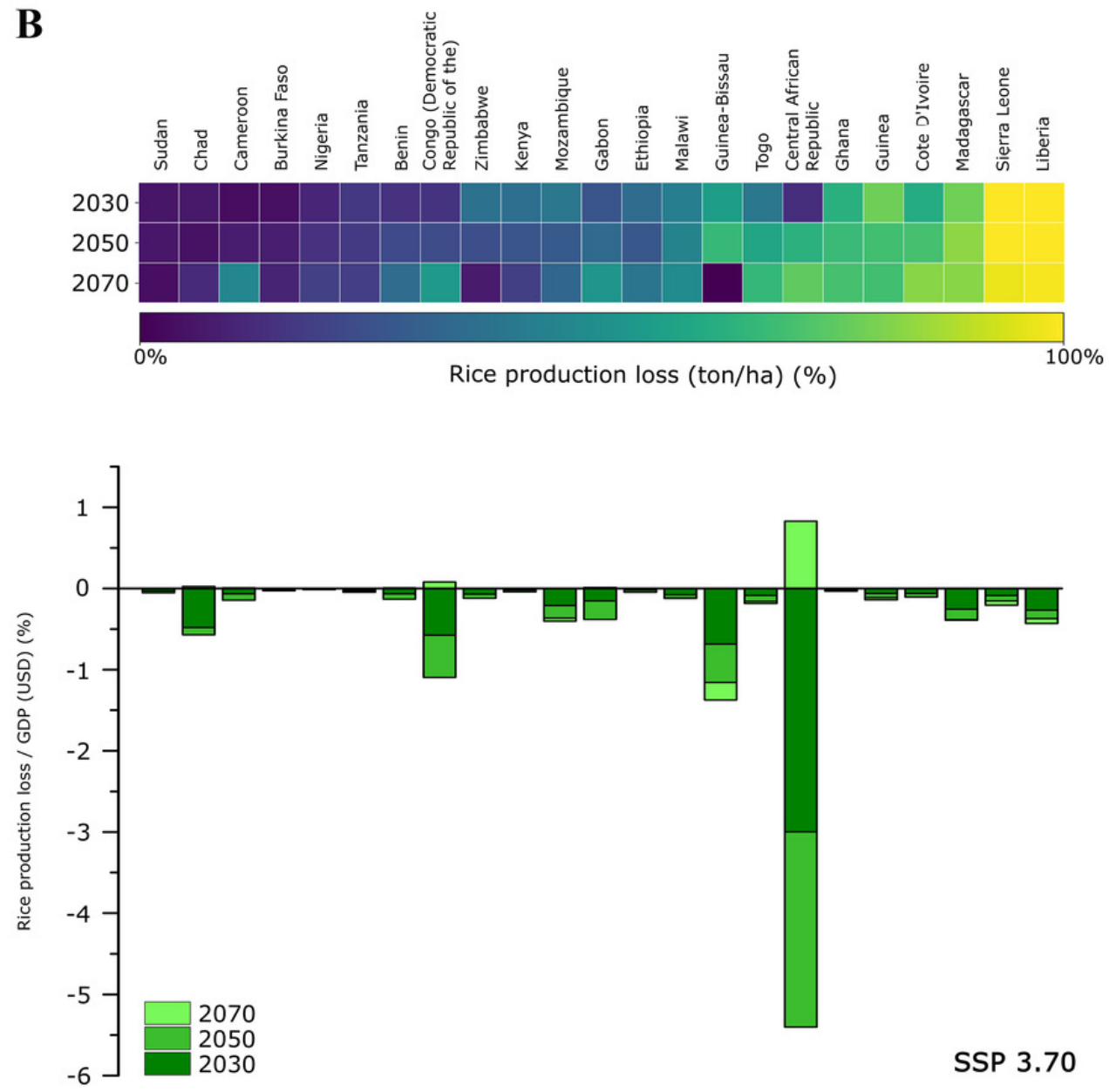